\title{
Impactos da Política Nacional de Irrigação sobre o desenvolvimento socioeconômico da região Norte de Minas Gerais: uma avaliação do Projeto Gorutuba
}

\author{
Paulo Ricardo da Costa Reis \\ Universidade Federal de Viçosa \\ Suely de Fátima Ramos Silveira \\ Universidade Federal de Viçosa \\ Pedro Eni Lourenço Rodrigues \\ Universidade Federal de Viçosa
}

\begin{abstract}
Este trabalho teve como objetivo identificar e avaliar os impactos socioeconômicos, diretos e indiretos, da Política Nacional de Irrigação. Especificamente, analisou-se a efetividade do Projeto Público de Irrigação Gorutuba, localizado no Norte de Minas Gerais. A pesquisa adota como metodologia a avaliação ex post facto, de impacto. Utilizando um modelo quase experimental, buscou-se, por meio da abordagem multivariada, comparar o município de Porteirinha, beneficiado com a implantação do Projeto Gorutuba, com municípios não beneficiados (grupo controle). Porteirinha ficou agrupado no cluster 6, juntamente com outros 13 municípios, todos pertencentes à região norte do estado, o que pode ser considerado uma evidência do bom desempenho do modelo para formação do grupo controle. A pesquisa evidenciou que o projeto alcança, em parte, os resultados esperados. Embora os resultados permitam reforçar a importância da agricultura irrigada na promoção do desenvolvimento regional, por meio dos impactos na produção agropecuária, na geração de empregos e crescimento populacional, identificou-se que os indicadores dos municípios analisados refletiram a ocorrência de crescimento econômico sem, entretanto, ter ocorrido melhoria dos indicadores sociais de Porteirinha (município beneficiado).
\end{abstract}

Palavras-chave: avaliação de política pública; projeto de irrigação; avaliação de impacto; indicadores socioeconômicos.

Impactos de la Política Nacional de Irrigación sobre el desarrollo socioeconómico de la región Norte de Minas Gerais: una evaluación del Proyecto Gorutuba

Este trabajo tuvo como objetivo identificar e evaluar los impactos socioeconómicos, directos e indirectos, de la Política Nacional de Irrigación. Específicamente se analizó la efectividad del Proyecto Público de

Artigo recebido em 20 out. 2010 e aceito em 20 abr. 2011. Os autores agradecem à Fapemig, ao CNPq e à Capes pelo financiamento e incentivo à pesquisa. 
Irrigación Gorutuba, ubicado en el Norte de Minas Gerais. La investigación adopta como metodología la evaluación ex post facto, de impacto. Utilizando un modelo casi-experimental se buscó, por medio del abordaje multivariado, comparar el municipio de Porteirinha, beneficiado con la implantación del Proyecto Gorutuba, con municipios no beneficiados (grupo control). Porteirinha quedó agrupado en el cluster 6, juntamente con otros 13 municipios, todos pertenecientes a la región Norte del Estado, lo que puede ser considerado una evidencia del buen desempeño del modelo para la formación del grupo control. La encuesta evidenció que el proyecto alcanza, en parte, los resultados esperados. Aunque los resultados permitan reforzar la importancia de la agricultura irrigada en la promoción del desarrollo regional, por medio de los impactos en la producción agropecuaria, en la generación de empleos y el crecimiento poblacional, se identificó que los indicadores de los municipios analizados reflejaron la ocurrencia de crecimiento económico sin, sin embargo, que haya ocurrido una mejoría de los indicadores sociales de Porteirinha (municipio beneficiado).

Palabras clave: evaluación de política pública; proyecto de irrigación; evaluación de impacto; indicadores socioeconómicos.

Impacts of the National Irrigation Policy on the socioeconomic development of the North Region of Minas Gerais State: an evaluation of Gorutuba Project

National Policy, and analyses the effectiveness of Gorutuba Irrigation Public Project, in the north of Minas Gerais. The methodology is the ex post facto evaluation. Throught a quasi experimental model, by means of multivariate statistics, the Porteirinha municipality, beneficiated by irrigation project, compared with non beneficiary municipalities (control group). The Porteirinha municipality was jointed in the cluster 6, with other 13 municipals, all of the North of Minas Gerais state, what can be interpreted as an evidence of the model for control group construcion's good performance. This research showed that irrigation project partially reaches expected results. The results of this study reinforce the importance of irrigated agriculture for regional development through the impacts in the agricultural production, in employment generation and population growth. Although the indicators of municipalities reflected the occurrence of economic growth, there was no improving of social indicators of Porteirinha (municipality benefited).

KEY WORDs: evaluation of public policy; irrigation project; impact assessment; socioeconomic indicators.

\section{Introdução}

O estado de Minas Gerais, localizado na região Sudeste, é o quarto estado brasileiro em extensão territorial, representando aproximadamente $7 \%$ da área total do país. Minas Gerais desempenha historicamente um importante papel no cenário nacional, em razão de sua localização geográfica, sua rica base de recursos naturais, sua produção agropecuária, mineral e industrial. O estado é composto por 853 municípios, distribuídos em 10 regiões de planejamento: Alto Paranaíba, Central, Centro-Oeste, Sul, Jequitinhonha Mucuri, Noroeste, Norte, Rio Doce, Triângulo e Zona da Mata. 
Não obstante, sérias desigualdades econômicas e sociais entre regiões e municípios coexistem no estado de Minas Gerais (Carneiro e Fontes, 2005). Silva, Fontes e Alves (2005), discorrendo sobre a dualidade do estado, ressaltam essas características, identificando regiões e municípios que alcançam alto desenvolvimento e prosperidade, enquanto, em outros, predominam atraso econômico e penúria, péssimos indicadores sociais e altos índices de pobreza. Diante desse cenário, especial atenção foi dada à região Norte do estado, tanto por iniciativa do governo estadual quanto do governo federal, no sentido de promover o desenvolvimento socioeconômico da região e reduzir as heterogeneidades sociais. A região norte de Minas é considerada como o início do polígono da seca brasileiro e engloba a maior parte da região semiárida mineira, sendo composta por sete microrregiões: Bocaiúva, Grão-Mogol, Janaúba, Januária, Montes Claros, Pirapora e Salinas.

Fundamentado na premissa de que a agricultura irrigada representa uma importante atividade para promover o desenvolvimento regional do semiárido brasileiro, o governo federal iniciou o ciclo político da então Política Nacional de Irrigação. Uma das principais ações da Política Nacional de Irrigação foi a implantação de projetos públicos de irrigação, através de iniciativa conjunta dos governos federal e estadual.

Em 1986, o governo José Sarney estabeleceu o Programa Nacional de Irrigação (Proni), que apresentava metas e objetivos para a Política Nacional de Irrigação (Proni, 1986). No estado de Minas Gerais, foi estabelecido o Plano Mineiro de Irrigação e Drenagem, que tinha como objetivo contribuir para o crescimento econômico-social do estado pela criação de empregos, distribuição de renda, aumento da produção agrícola, melhoria do abastecimento interno e formação de excedentes exportáveis (PMID, 1986). Deste modo, em sua concepção, a Política Nacional de Irrigação tinha duas frentes distintas, porém complementares: aprimorar a agricultura do país através de tecnologia e desenvolver de forma sustentável (com foco nos extratos mais pobres da população) a economia nacional.

Embora a implementação da Política Nacional de Irrigação tivesse como objetivo a promoção do desenvolvimento socioeconômico de regiões menos favorecidas, ainda não há um consenso sobre seus resultados, que possibilite direcionar as ações do poder público e prestar contas à sociedade sobre a aplicação dos recursos. Além disso, muito se tem questionado sobre a necessidade de definir e/ou aplicar metodologias de análise de políticas e programas públicos como forma de introduzir mecanismos de incentivo à eficiência, eficácia, efetividade e accountability na administração pública.

Este artigo teve como foco a avaliação dos resultados e impactos da Política Nacional de Irrigação. Tanto no Brasil como em outros países, os estudos sobre políticas públicas estão voltados principalmente para a etapa de formulação. Entretanto, observa-se a necessidade de elaboração de estudos sobre a etapa de avaliação. A avaliação na administração pública significa determinar o mérito e a prioridade de um projeto de investimento ou de um projeto social, geralmente financiado com recursos públicos e direcionado para resolver um determinado problema econômico ou social (Holanda, 2003). De forma mais pragmática e direcionada ao objetivo deste trabalho, o grande desafio na avaliação de política pública é o 
desenvolvimento de sistemas que tracem e especifiquem as mudanças nas condições de vida da população beneficiada diretamente pela política (Dale, 2004).

Da perspectiva das análises avaliativas, este trabalho visa contribuir avaliando os impactos socioeconômicos inerentes à implantação do Projeto Público de Irrigação do Gorutuba na bacia do rio São Francisco, no município de Porteirinha, região Norte do estado de Minas Gerais. Ressalta-se que as políticas públicas para promoção do desenvolvimento regional devem buscar não somente o aumento da produção e produtividade, mas também a melhoria das condições de vida da população em geral sem comprometer as gerações futuras, garantindo a preservação do patrimônio natural, ou seja, é necessário clareza na distinção de desenvolvimento e crescimento econômico (Rodrigues, 2001).

$\mathrm{O}$ artigo foi estruturado em sete seções. Além desta, introdutória, tem-se a seção 2 que apresenta o histórico e contextualiza a situação atual do Projeto de Irrigação Gorutuba. Na terceira seção, aborda-se a Política Nacional de Irrigação e o desenvolvimento regional; na quarta, discute-se a avaliação de políticas e programas públicos e, na quinta, os procedimentos metodológicos; na sexta, têm-se os resultados e discussão; e na sétima seção apresentamse as conclusões desta pesquisa.

\section{Projeto de Irrigação Gorutuba}

O Projeto de Irrigação Gorutuba, implantado em 1978 no município de Porteirinha, atualmente localiza-se em Nova Porteirinha, no Norte de Minas Gerais, às margens do rio Gorutuba. ${ }^{1}$ O Perímetro Irrigado do Gorutuba é um empreendimento da Companhia de Desenvolvimento dos Vales do São Francisco e do Paranaíba (Codevasf), gerido pelo Distrito de Irrigação do Gorutuba (DIG) em parceria com o governo de Minas Gerais. O projeto abrange uma área de 7.172 ha, sendo 4.818 ha irrigáveis, divididos em duas áreas, de grandes produtores (empresários) e de pequenos produtores (colonos), sendo a primeira subdividida em 52 lotes e a segunda em 11 colonizações com 391 lotes.

A agricultura familiar tem destacada importância no projeto visto que, segundo a Empresa de Assistência Técnica e Extensão Rural do Estado de Minas Gerais (Emater, 2006), são 426 famílias trabalhando em áreas médias de 5 a 10 ha. As principais culturas do perímetro são banana, manga, acerola, citros, goiaba, uva, milho, maracujá, arroz, feijão, hortaliças e sementes, sendo a banana a cultura predominante.

Na tabela 1 apresentam-se a área em produção, o volume de produção e o valor comercializado por colonos e empresários no Perímetro Irrigado de Gorutuba, durante o período de 1995 a 2005.

\footnotetext{
${ }^{1}$ Por emancipação política através da Lei n⿳ำ 12.030, de 21 de dezembro de 1995, o município de Nova Porteirinha foi desmembrado do município de Porteirinha.
} 
Tabela 1

Área em produção, o volume de produção e o valor comercializado por colonos e empresários no Perímetro Irrigado de Gorutuba (1995-2005)

\begin{tabular}{|rcccccccccc|}
\hline & \multicolumn{3}{c}{ Área em produção (ha) } & \multicolumn{3}{c}{ Produção obtida (t) } & \multicolumn{3}{c|}{ Valor comercializado (Mil R\$) } \\
& Colonos & Empresários & Total & Colonos & Empresários & Total & Colonos & Empresários & Total \\
\hline 1995 & 1.107 & 1.044 & 2.151 & 9.866 & 13.744 & 23.611 & $3.554,35$ & $7.259,40$ & $10.813,75$ \\
1996 & 1.380 & 1.028 & 2.408 & 13.418 & 14.004 & 27.422 & $3.975,50$ & $5.833,50$ & $9.809,01$ \\
1997 & 1.551 & 1.221 & 2.772 & 22.258 & 16.240 & 38.498 & $3.577,48$ & $3.797,93$ & $7.375,41$ \\
1998 & - & - & - & - & - & - & - & - & - \\
1999 & 1.688 & 1.043 & 2.732 & 23.537 & 12.565 & 36.102 & $5.588,14$ & $3.104,10$ & $8.692,24$ \\
2000 & 1.622 & 1.177 & 2.799 & 23.798 & 18.910 & 42.709 & $4.974,18$ & $4.801,65$ & $9.775,83$ \\
2001 & 1.606 & 1.138 & 2.744 & 24.261 & 17.131 & 41.392 & $6.118,38$ & $3.901,82$ & $10.020,20$ \\
2002 & 1.487 & 1.243 & 2.729 & 19.982 & 25.112 & 45.094 & $5.180,29$ & $6.702,90$ & $11.883,19$ \\
2003 & 1.665 & 1.371 & 3.036 & 18.709 & 23.361 & 42.071 & $7.410,91$ & $7.023,94$ & $14.434,85$ \\
2004 & 1.823 & 1.403 & 3.226 & 18.416 & 25.813 & 44.229 & $7.795,20$ & $9.963,69$ & $17.758,89$ \\
2005 & 1.636 & 1.318 & 2.954 & 18.490 & 25.823 & 44.312 & $6.435,80$ & $9.074,76$ & $15.510,56$ \\
\hline
\end{tabular}

Fonte: Elaborado pelos autores a partir de dados da Codevasf.

Nota. (-) Dados não disponíveis.

O volume de produção do perímetro, em 2005, atingiu 42.070,65 toneladas, produzidas em uma área de 3.065,99 ha. Essa produção gerou uma receita bruta de $\mathrm{R} \$ 15.510 .564,00$, em que os pequenos produtores tiveram uma participação de 41,49\% contra 58,51\% dos empresários.

No período analisado, a área total em produção no perímetro apresentou um crescimento de 37,34\% (colonos 47,71\%, empresários 26,34\%), o volume total de produção apresentou um crescimento de $87,68 \%$ (colonos $87,40 \%$, empresários $87,88 \%$ ) e o volume total comercializado de 1995 a 2005 apresentou uma taxa de crescimento de 43,43\%, sendo os colonos responsáveis por $81,07 \%$ deste crescimento, enquanto os empresários foram responsáveis por $25,01 \%$.

\section{Política Nacional de Irrigação e desenvolvimento regional}

A região Norte de Minas Gerais é considerada como o início da região semiárida do Nordeste brasileiro e está inserida na área denominada Polígono da Seca, que é caracterizada por uma ocupação inexpressiva e de baixa produtividade, decorrente de sua base técnica atrasada, somada a problemas climáticos, que contribuem para a intensificação de movimentos migratórios em direção a regiões mais desenvolvidas.

Com o intuito de transformar este cenário de subdesenvolvimento, bem como amenizar os problemas ocasionados pela irregularidade climática típica da região, a partir da década de 
1950, as autoridades governamentais, baseadas no conhecimento das potencialidades econômicas do Vale do São Francisco, deram início ao desenvolvimento da agricultura irrigada na região, por meio da implementação da Política Nacional de Irrigação.

A implementação do programa de irrigação pública no Brasil iniciou-se na década de 1960, caracterizando-se pela implantação de projetos públicos de irrigação como fator de dinamização da economia regional, geração de empregos, retenção de migrantes e redução da pobreza (Passador, Passador e Moreira, 2009).

A irrigação é uma prática agrícola com uso intensivo de tecnologia, que coloca o recurso produtivo água sob controle do agricultor, eliminando riscos de perdas ocasionadas por estiagens e secas. Ao mesmo tempo, possibilita maior produtividade pelo uso mais eficiente de insumos, como máquinas, equipamentos, fertilizantes, defensivos, sementes melhoradas, energia elétrica e mão de obra (Proni, 1986).

Quanto ao aspecto econômico, espera-se que a irrigação possibilite aumento na produção, elevando o nível de renda do produtor e, consequentemente, dinamizando a economia na região. No aspecto sociocultural, a irrigação é um fator indutor de mudanças que poderão ser observadas no comportamento das pessoas (Bernardo, Soares e Mantovani, 2005). A irrigação exerce importante papel nas regiões com clima semiárido, garantindo sustentabilidade econômica à atividade agrícola, minimizando principalmente o risco tecnológico, representado pela escassez de água, além de contribuir para (i) criação de empregos, (ii) inserção da dimensão competitiva e da modernização produtiva na agricultura, (iii) fixação do homem no campo, (iv) oferta de alimento nos períodos de entressafra e (v) redução dos desequilíbrios regionais e sociais.

Neste sentido, a Política Nacional de Irrigação teve como objetivo o aproveitamento racional de recursos de água e solos para a implantação e o desenvolvimento da agricultura irrigada, obedecendo aos seguintes postulados básicos: (i) preeminência da função social e utilidade pública do uso da água e solos irrigáveis; (ii) estímulo e maior segurança às atividades agropecuárias, prioritariamente, nas regiões sujeitas a condições climáticas adversas; (iii) promoção de condições que possam elevar a produção e a produtividade agrícolas; e (iv) atuação principal ou supletiva do poder público na elaboração, financiamento, execução, operação, fiscalização e acompanhamento de projetos de irrigação.

De acordo com a Lei no 6.662/1979, os projetos de irrigação podem ser públicos ou privados. Os projetos públicos são aqueles cuja infraestrutura de irrigação é projetada, implantada e operada, direta ou indiretamente, sob a responsabilidade do poder público. Os projetos privados são aqueles cuja infraestrutura de irrigação é projetada, implantada e operada por particulares, com ou sem incentivos do setor público.

Os projetos públicos de irrigação serão localizados, prioritariamente, em terras do patrimônio público, para esse fim reservadas ou adquiridas. Os perímetros irrigados serão sempre destinados à exploração intensiva da atividade agropecuária ou agroindustrial, e divididos em lotes de dimensões variáveis de acordo com a estrutura de produção projetada, observados os critérios estabelecidos pelo Ministério do Interior (Lei no 6.662, de 25 de junho de 1979). Os lotes poderão ser alienados ou cedidos a irrigantes ou cooperativas ou, ainda, incorporados 
ao capital social de empresas ou sociedades civis que tenham como objetivo a agricultura irrigada.

\section{Avaliação de políticas e programas públicos}

A importância e a preocupação com os resultados e impactos sociais desejados de uma política pública se dão, em um extremo, pelas restrições dos recursos públicos e, no outro, por questões legítimas, que auxiliam no entendimento assim como em esclarecimentos úteis e indispensáveis acerca dos complexos problemas de gerenciamento envolvidos na administração pública. De acordo com Marinho e Façanha (2001), esses problemas da gestão pública concedem importância significativa e proeminente às atividades de avaliação, adquirindo condição de instrumento central e indispensável de gestão.

Soares e Pianto (2003) diferenciam a avaliação em dois níveis, sendo o primeiro de processo, que analisa como os recursos foram utilizados, enquanto o segundo estima o resultado. Apesar da diferença, qualquer modelo de avaliação visa obter informações úteis e críveis sobre o desempenho de programas e políticas públicas, identificando problemas e limitações, potencialidades e alternativas, bem como levantando práticas mais eficientes (Holanda, 2003).

Diversos estudos da área chamam a atenção para quatro conceitos, que não devem ser confundidos no processo de avaliação: efetividade, eficiência, eficácia e accountability (Dale, 2004; Rossi, Lipsey e Freeman, 2004; Bardach, 2005; Neubert, 2000). O conceito de efetividade diz respeito à capacidade de se promoverem resultados pretendidos; a eficiência denota competência para se produzirem resultados com dispêndio mínimo de recursos e esforços; e a eficácia remete a condições controladas e resultados desejados de experimentos. Por fim, de acordo com Doherty e Horne (2002), accountability na administração pública tem por objetivo prevenir fraudes e corrupção e assegurar que as verbas sejam usadas para os devidos propósitos, auxiliando os responsáveis pelo gerenciamento dos recursos públicos a alcançar economia, eficiência e eficácia de maneira ética e transparente.

Para este estudo, buscou-se avaliar a efetividade da Política Nacional de Irrigação, especificamente do Projeto de Irrigação Gorutuba, isto é, avaliar se os resultados pretendidos com a implantação do Projeto de Irrigação Gorutuba foram alcançados. Há de se ressalvar que a avaliação de resultados ou avaliação de impacto é um método de avaliação ex post facto e que, de acordo com Ferro e Kassouf (2004), ocorre após a implementação do projeto e consiste na comparação de beneficiários observados com não beneficiários (também conhecidos como grupo controle), avaliando dessa maneira o impacto do projeto.

A avaliação de impacto adquiriu significados diferentes durante os últimos 20 anos. As definições mais comuns são:

(a) uma avaliação que analisa os impactos do bem-estar da população a partir de uma intervenção, ao invés de apenas os resultados diretos desta, ou de uma avaliação de processo, que tem o foco na implementação; (b) uma avaliação preocupada em estabelecer os resultados diretos e 
indiretos, bem como os esperados e os não esperados. Por exemplo, a diferença com o projeto e sem o projeto (como os indicadores se comportam com o projeto, comparando-se como eles se comportariam sem o projeto); (c) uma avaliação realizada algum tempo (cinco ou 10 anos) após a intervenção ter sido completada, de modo a permitir que os impactos apareçam e; (d) uma avaliação que considera todas as intervenções de um determinado setor ou área geográfica (White, 2007:1, tradução nossa).

Nesse sentido, a avaliação de impacto deve considerar um grupo de indicadores que sejam utilizados para definir, averiguar e mensurar os inputs do programa, seu processo de implementação e seus outputs, entendidos aqui como resultados ou impacto. É necessário apresentar um sistema lógico, que avalie impactos inesperados, baseando-se em argumentos plausíveis por meio de indicadores (tais como desenvolvimento da economia local) após a intervenção, utilizando-os como ferramentas de comparação com uma situação "sem intervenção". Por fim, de acordo com procedimentos estatísticos aceitáveis, é preciso mensurar como a intervenção impactou e beneficiou a população-alvo (World Bank, 2006).

\section{Procedimentos metodológicos}

\section{1 Área de estudo}

A amostra é formada por 107 municípios localizados no vale do São Francisco, no estado de Minas Gerais em 1970, período anterior à implantação do Projeto Gorutuba. Nesse período, a bacia do rio São Francisco (MG) era formada por 209 municípios. No entanto, para fins desta pesquisa, consideraram-se apenas os municípios com população residente entre 5 mil e 50 mil habitantes e Produto Interno Bruto (PIB) entre 5 milhões e 50 milhões de reais. Além desses critérios, também foram excluídos da observação os municípios de Piracema e Passa Tempo, devido à indisponibilidade de informações referentes a algumas variáveis desses municípios no período analisado.

Ressalta-se que, após a Constituição de 1988, ocorreu um intenso processo de emancipação municipal em todo o país. Em 1970, a região do vale do São Francisco em Minas Gerais possuía 209 municípios e atualmente são 259. Para a análise do impacto do perímetro irrigado, optou-se por reagrupar os municípios emancipados a partir de 1970. Assim, os municípios foram recompostos, reconstituindo-se a estrutura original da época da implementação do perímetro irrigado, isto é, os dados dos municípios emancipados foram agregados a seus municípios de origem para que a análise fosse realizada sob as mesmas condições do cluster obtido. Assim, o município beneficiado pelo projeto Gorutuba, originalmente, foi o município de Porteirinha, no qual o projeto foi implantado inicialmente.

A escolha da bacia do rio São Francisco justifica-se em razão do grande volume de investimentos públicos na região, durante as últimas cinco décadas. Entre estes, há importantes 
projetos públicos de irrigação (Projeto Gorutuba, Projeto Jaíba, Projeto Lagoa Grande e Projeto Pirapora), sendo todos implantados na região Norte do estado com intuito de promover o desenvolvimento local através da agricultura irrigada, aproveitando as aptidões da região para a atividade agrícola.

É importante ressaltar, também, que a bacia do São Francisco é região pioneira na agricultura e fruticultura irrigadas no país. No estado de Minas Gerais sua região Norte é um importante polo da fruticultura irrigada.

\subsection{Fonte dos dados}

O perfil e as características socioeconômicas de um município possuem caráter multidimensional, razão pela qual se torna necessário um expressivo número de variáveis (econômicas, sociais, demográficas e de infraestrutura, entre outras) para caracterizá-los de forma abrangente. Assim, com o intuito de mensurar esses aspectos, foram selecionadas 18 variáveis para cada um dos 107 municípios que compõem a amostra. As seguintes variáveis foram selecionadas: Sociais (X1: Renda familiar — per capita — média — Salário Mínimo; X2: Índice de Desenvolvimento Humano — Longevidade; X3: Índice de Desenvolvimento Humano — Renda; X4: Índice de Desenvolvimento Humano — Educação; X5: Evasão Escolar — Pessoas na faixa etária de 10 a 14 anos trabalhando (\%); X6: Esperança de vida ao nascer — Ano e X7: Mortalidade Infantil (por mil nascidos vivos); Econômicas (X8: PIB Municipal — R\$ de 2000 (mil); X9: PIB Municipal — Agropecuária R\$ de 2000 (mil); X10: Produção Lavoura Temporária — R\$ de 2000 (mil) e X11: Produção Lavoura Permanente — R\$ de 2000 (mil) e Demográficas (X12: Domicílios com Iluminação Elétrica — Domicílios; X13: População Residente Rural — Habitante; X14: População Residente Urbana - Habitante; X15: População Ocupada Rural — Pessoa; X16: População Ocupada Urbana — Pessoa; X17: População Economicamente Ativa Rural — Pessoa e X18: População Economicamente Ativa Urbana — Pessoa).

As variáveis utilizadas foram obtidas junto ao banco de dados on-line do Instituto de Pesquisa Econômica Aplicada (Ipeadata).

\subsection{Classificação da pesquisa e tratamento dos dados}

A pesquisa fundamentou-se em um modelo quase experimental, por meio de técnicas estatísticas de análise multivariada (análise fatorial e análise de clusters), realizando-se uma comparação entre o desempenho do município beneficiado (Porteirinha) e o grupo controle, ou seja, municípios que não receberam investimentos diretos da Política Nacional de Irrigação.

De acordo com Rossi, Lipsey e Freeman (2004), precursores da metodologia, o modelo quase experimental é, comumente, utilizado para avaliar o impacto de um programa quando não é possível avaliar o processo como um todo. A razão é justamente devido às intervenções 
estarem fora de controle do avaliador e sendo afetadas por fatores políticos e éticos, além de outros como os que envolvem os stakeholders da política.

O modelo dos grupos controle não equivalentes, ou de comparação, forma grupos "com projeto" (beneficiados) e "sem projeto" (não beneficiados). Supõe-se, através de agrupamento estatístico, que os membros não contemplados tenham características semelhantes àquelas dos que integram o grupo de beneficiários, antes da implantação do projeto. Este modelo permite que o pesquisador observe como estaria determinado município ou região, caso não houvesse projeto, e quais os impactos gerados pelo projeto, através da análise comparativa do grupo de beneficiados e do grupo controle (Cohen e Franco, 2007). Segundo o World Bank (2006), o pesquisador identifica as características que serão comparadas e as áreas do projeto que serão observadas.

\subsection{Análise fatorial}

A análise fatorial é um conjunto de técnicas estatísticas que procura explicar a correlação entre as variáveis observadas, simplificando os dados pela redução do número de variáveis necessárias para descrevê-los (Pestana e Gageiro, 2005). Segundo Mingoti (2005), o objetivo da análise fatorial é descrever o comportamento de determinado conjunto de variáveis, a partir da estrutura de dependência entre elas, por meio de um número menor de variáveis denominadas fatores. As variáveis mais correlacionadas se combinam num mesmo fator, sendo estas independentes daquelas que compõem outro fator, ou seja, os fatores não são correlacionados entre si.

Para realização da Análise Fatorial Exploratória (AFE), uma opção consiste em utilizar o método de extração de fatores denominado Método das Componentes Principais com rotação ortogonal, de modo a serem independentes entre si. Utilizou-se o método de rotação Varimax. O método dos componentes principais faz com que o primeiro fator contenha o maior percentual de explicação da variância total, o segundo fator tenha o segundo maior percentual e, assim, sucessivamente.

O modelo fatorial obtido explicita, teoricamente, a estrutura de fatores latentes responsáveis pelas correlações observadas entre as variáveis originais. Naturalmente, o modelo assume que existe um número de fatores inferiores ao número de variáveis originais, que são capazes de explicar uma percentagem elevada da variância total das variáveis originais. As regras do eigenvalue (raiz característica) superior a um e Scree-plot são, geralmente, utilizadas para decidir o número mínimo de fatores necessários para explicar uma proporção considerável da variância total dos dados originais.

Para avaliar a validade da AFE, foram utilizados o critério Kaiser-Meyer-Olkin (KMO), o Teste de Bartlett, o Scree Plot e a percentagem de variância total. O KMO e o Teste de Bartlett são dois procedimentos estatísticos que permitem medir a qualidade das correlações entre as variáveis de modo a prosseguir com a análise fatorial. 


\subsection{Análise de clusters}

Após a redução dos fatores, foi realizada a análise de cluster, que tem como objetivo agrupar objetos ou indivíduos segundo suas características fundamentais, formando grupos ou conglomerados semelhantes. De acordo com Hair Junior e colaboradores (2005), os elementos em cada conglomerado tendem a ser semelhantes entre si, porém diferentes das demais pertencentes aos outros conglomerados. Sendo este o mesmo propósito perseguido pela metodologia de grupo controle, o procedimento multivariado torna-se, portanto, mais adequado aos objetivos do trabalho.

Existem basicamente dois métodos de análise de clusters: o agrupamento hierárquico e o agrupamento não hierárquico. O primeiro método permite a obtenção de clusters tanto para objetos quanto para variáveis, enquanto o segundo método é válido apenas para obtenção de clusters de sujeitos (Maroco, 2007). Os métodos não hierárquicos destinam-se a reunir os objetos num conjunto de grupos, que deve ser previamente definido pelo analista. No entanto, os procedimentos hierárquicos recorrem a passos sucessivos de agregação dos sujeitos, na formação de uma estrutura hierárquica, podendo seguir a via aglomerativa ou, pelo contrário, a via divisível.

Neste trabalho, utilizou-se o método hierárquico aglomerativo de Ward. O procedimento básico consiste em computar uma matriz de distância ou similaridade entre os indivíduos, a partir da qual se inicia um processo de sucessivas fusões destes, com base na proximidade ou similaridade entre eles.

Todos os cálculos para o agrupamento dos municípios foram efetuados a partir da utilização do software SPSS (Statistical Package for the Social Sciences), versão 15.0, licenciado.

\subsection{Análise temporal}

Para analisar a evolução dos indicadores socioeconômicos do município beneficiado e dos municípios que compõem o grupo controle e a percepção do comportamento desses indicadores no contexto pré e pós-implantação do Projeto Gorutuba, foram delimitados como corte analítico os anos de 1970 a 2000, em razão de 1970 a 1980 ser considerado o período préimplementação e o de 1980 a 2000, pós-implementação desse projeto público de irrigação.

A análise da evolução e comparação dos dados foi realizada a partir da Taxa Média Geométrica (TMGC) e da Taxa Média de Crescimento (TC).

A Taxa Média Geométrica de Crescimento é, em geral, utilizada em ciências sociais aplicadas para descrever variações das médias compostas, a partir do conceito de progressão geométrica (Triola, 2005). Esta taxa é relevante nesse estudo, pois apresenta a média de crescimento interperíodo.

$$
\text { TMGCA }=\sqrt[t]{\frac{P_{\mathrm{t}}}{P_{0}}}-1
$$


em que:

TMGCA: taxa média geométrica de crescimento anual.

$\mathrm{P}_{\mathrm{t}}$ : valor final.

$\mathrm{P}_{0}$ : valor inicial.

t: número de períodos de variação.

A Taxa Média de Crescimento consubstancia-se na taxa média de variação do índice, composta anualmente entre períodos, sendo importante para o estudo, visto que apresenta a média de crescimento de todo o período estudado (1970 a 2000).

$$
T M C=\left(\frac{P_{t}-P_{0}}{P_{0}}\right)
$$

em que:

TMC: taxa média de crescimento.

$\mathrm{P}_{\mathrm{t}}$ : valor final.

$\mathrm{P}_{0}$ : valor inicial.

\section{Resultados e discussão}

Esta seção será dividida em duas vertentes. Uma que contempla resultados e discussões dos procedimentos estatísticos de análise multivariada adotados, explicitando o processo de redução dos dados e a formação do grupo controle através da análise de clusters. A segunda traz uma contextualização e apresentação dos impactos socioeconômicos (diretos e indiretos) do projeto público de irrigação, comparando o município beneficiado com o grupo controle, antes e após a implantação do Projeto Gorutuba.

\subsection{Redução das variáveis e formação do grupo controle}

Visando agrupar as 18 variáveis selecionadas dos municípios que compõem a amostra, realizou-se o procedimento de análise fatorial. A tabela 2 apresenta as estatísticas descritivas das variáveis utilizadas na análise fatorial.

A partir da análise exploratória dos dados, percebe-se que os indicadores sociais foram os que apresentaram menor dispersão, o que evidencia a homogeneidade dos 107 municípios analisados, no ano de 1970. Enquanto os resultados referentes às variáveis econômicas e demográficas demonstraram que os dados dos municípios investigados apresentam maiores dispersões. 
Tabela 2

Estatística descritiva das variáveis utilizadas na construção dos fatores (1970)

\begin{tabular}{|lcccc|}
\hline Variáveis & Média & Desvio Padrão & Assimetria & Curtose \\
\hline Renda Familiar per Capita Média Sal. Mín. & 0,33 & 0,09 & 0,14 & $-0,61$ \\
Índice de Desenvolvimento Humano Longevidade & 0,44 & 0,05 & $-0,22$ & $-0,17$ \\
Índice de Desenvolvimento Humano Renda & 0,21 & 0,07 & 0,15 & $-0,61$ \\
Índice de Desenvolvimento Humano Educação & 0,44 & 0,11 & $-0,92$ & 0,17 \\
Evasão Escolar - Pessoas 10 a 14 anos trab. (\%) & 11,01 & 5,28 & 1,19 & 1,99 \\
Esperança de Vida ao Nascer - Ano & 51,30 & 2,78 & $-0,22$ & $-0,18$ \\
Mortalidade Infantil (por mil nascidos vivos) & 101,63 & 19,01 & 0,50 & 0,00 \\
PIB Municipal - R\$ de 2.000 (mil) & $17.920,71$ & $11.460,17$ & 1,00 & 0,07 \\
PIB Municipal - agropecuária R\$ de 2.000 (mil) & $6.936,16$ & $5.030,21$ & 1,64 & 3,00 \\
Produção Lavoura Temp. - R\$ de 2.000 (mil) & $4.176,33$ & $4.772,52$ & 4,02 & 25,20 \\
Produção Lavoura Perm. - R\$ de 2.000 (mil) & 339 & 399 & 2,55 & 7,98 \\
Domićlios com Iluminação Elétrica - Domićlios & 588 & 552 & 1,70 & 2,79 \\
População Residente Rural - Habitante & 9.090 & 7.180 & 1,89 & 3,37 \\
População Residente Urbana - Habitante & 5.243 & 3.967 & 1,76 & 3,31 \\
População Ocupada Rural - Pessoa & 2.739 & 2.187 & 1,99 & 3,96 \\
População Ocupada Urbana - Pessoa & 1.411 & 1.062 & 1,60 & 2,75 \\
População Economicamente Ativa Rural - Pessoa & 2.754 & 2.188 & 1,98 & 3,92 \\
População Economicamente Ativa Urbana - Pessoa & 1.440 & 1.089 & 1,63 & 2,86 \\
\hline
\end{tabular}

Fonte: Resultados da pesquisa.

A análise fatorial resultou na extração de quatro fatores com raiz característica (eigenvalues) superiores a um e que respondem, em conjunto, por 85,1\% da variância total dos dados (34,9\% Fator 1, 27,2\% Fator 2, 17\% Fator 3 e 6\% Fator 4). As variáveis apresentaram bom ajustamento, representado pelo resultado do teste de Kaiser-Meyer-Olkin (KMO), com coeficiente de 0,790, com nível de significância de 0,000 pelo Teste de Barlett, o que pode ser considerado uma boa recomendação para proceder à análise fatorial.

Na tabela 3 são apresentadas as cargas fatoriais mais acentuadas de cada variável, ou seja, os maiores coeficientes de correlação entre a variável e o fator. Optou-se por apresentar apenas as variáveis que apresentaram scores superiores a 0,60, sugerindo quatro fatores: Ru- 
ral, Urbano, Saúde e Produção Agrícola Permanente. ${ }^{2}$ Em seguida, procurou-se explicar cada um dos quatros fatores gerados.

Tabela 3

Matriz de componentes após rotação ortogonal (1970)

\begin{tabular}{|c|c|c|c|c|}
\hline \multirow[t]{2}{*}{ Variáveis } & \multicolumn{4}{|c|}{ Fator } \\
\hline & 1 & 2 & 3 & 4 \\
\hline População Ocupada - Rural - Pessoa & 0,962 & & & \\
\hline População Economicamente Ativa - Rural - Pessoa & 0,961 & & & \\
\hline População Residente - Rural - Habitante & 0,956 & & & \\
\hline Índice de Desenvolvimento Humano Educação & $-0,833$ & & & \\
\hline PIB Municipal - Agropecuária R\$ de 2.000 (mil) & 0,705 & & & \\
\hline Índice de Desenvolvimento Humano Renda & $-0,634$ & & & \\
\hline População Ocupada - Urbana - Pessoa & & 0,979 & & \\
\hline População Economicamente Ativa - Urbana - Pessoa & & 0,979 & & \\
\hline População Residente - Urbana - Habitante & & 0,976 & & \\
\hline Domicílios - com lluminação Elétrica & & 0,924 & & \\
\hline PIB Municipal - R\$ de 2.000 (mil) & & 0,839 & & \\
\hline Índice de Desenvolvimento Humano Longevidade & & & 0,998 & \\
\hline Esperança de Vida ao Nascer - Ano & & & 0,998 & \\
\hline Mortalidade Infantil (por mil nascidos vivos) & & & $-0,997$ & \\
\hline Produção - Lavoura Permanente - R\$ de 2.000 (mil) & & & & 0,764 \\
\hline Variância Explicada pelo Fator (\%) & 34,90 & 27,20 & 17,00 & 6,00 \\
\hline
\end{tabular}

Fonte: Resultados da pesquisa.

Fator 1 (Rural): O fator 1 permite dimensionar a concentração de pessoas no campo, as condições de acesso a educação e a renda para essa população e o valor da produção gerada pela atividade agropecuária. As variáveis IDH renda e IDH educação apresentam correlação negativa, enquanto as variáveis população residente, população economicamente ativa e população ocupada, ambas na zona rural, assim como o produto interno bruto da atividade

${ }^{2}$ As variáveis: Renda Familiar — per capita, Evasão Escolar e Produção Lavoura Temporária apresentaram cargas fatoriais com valor inferior a 0,60; isso significa que essas variáveis não estão fortemente associadas a nenhum fator. 
agropecuária, apresentaram correlação positiva. Essas correlações sugerem que o fator rural é marcado por baixo acesso a educação e a renda.

Fator 2 (Urbano): Evidencia o perfil urbano do município, pois está diretamente relacionado às variáveis como domicílios com iluminação elétrica, população residente, população economicamente ativa e população ocupada, todas urbanas, e o produto interno bruto municipal. Todas as variáveis possuem alta correlação positiva com o fator, expressando um perfil de município com características urbanas, com acesso a energia elétrica, a maioria da população residindo e trabalhando na cidade, certamente em atividades como comércio, serviço e indústria, proporcionando uma maior atividade econômica no município e, consequentemente, gerando um PIB mais elevado.

Fator 3 (Saúde): Caracteriza o município em relação às variáveis referentes às condições de acesso a saúde e a expectativa de vida. As variáveis IDH longevidade e esperança de vida ao nascer apresentam elevada correlação positiva, e a taxa de mortalidade infantil apresenta elevada correlação negativa com o fator.

Fator 4 (Produção Agrícola Permanente): Este fator foi representado apenas pela variável valor da produção agrícola (lavoura) permanente. A atividade agrícola permanente ou lavoura permanente compreende a área plantada ou em preparo para o plantio de culturas perenes, tais como café, laranja, cacau, banana e uva.

Com intuito de definir o grupo controle, procedeu-se à análise de clusters, por meio da qual os municípios foram agrupados de acordo com os escores fatoriais dos quatros fatores obtidos (Rural, Urbano, Saúde e Produção Agrícola Permanente). Assim, os 107 municípios que compõem a amostra foram classificados em sete grupos, conglomerados ou clusters distintos. A representação dos agrupamentos pode ser observada na figura 1, que representa o mapa da América do Sul, o Brasil, o estado de Minas Gerais e, no destaque, a região da bacia do São Francisco inserida no estado.

O município de Porteirinha, no qual o Projeto Gorutuba foi implantado em 1978, ficou agrupado no cluster 6, juntamente com outros 13 municípios: Bocaiúva, Brasília de Minas, Coração de Jesus, Espinosa, Francisco Sá, Grão Mogol, Janaúba, Manga, Montalvânia, Monte Azul, Rio Pardo de Minas, São João da Ponte e Varzelândia, sendo todos pertencentes à região Norte do Estado, o que pode ser considerado uma evidência do bom desempenho do modelo para formação do grupo controle.

No entanto, verifica-se que o município de Manga também foi contemplado pela Política Nacional de Irrigação, com a implantação do Projeto Jaíba, maior projeto irrigado da América Latina. Levando-se em consideração a metodologia adotada, optou-se por excluir o município de Manga do grupo controle. 
Figura 1

Área da bacia do rio São Francisco, em Minas Gerais, dividida em sete clusters (1970)

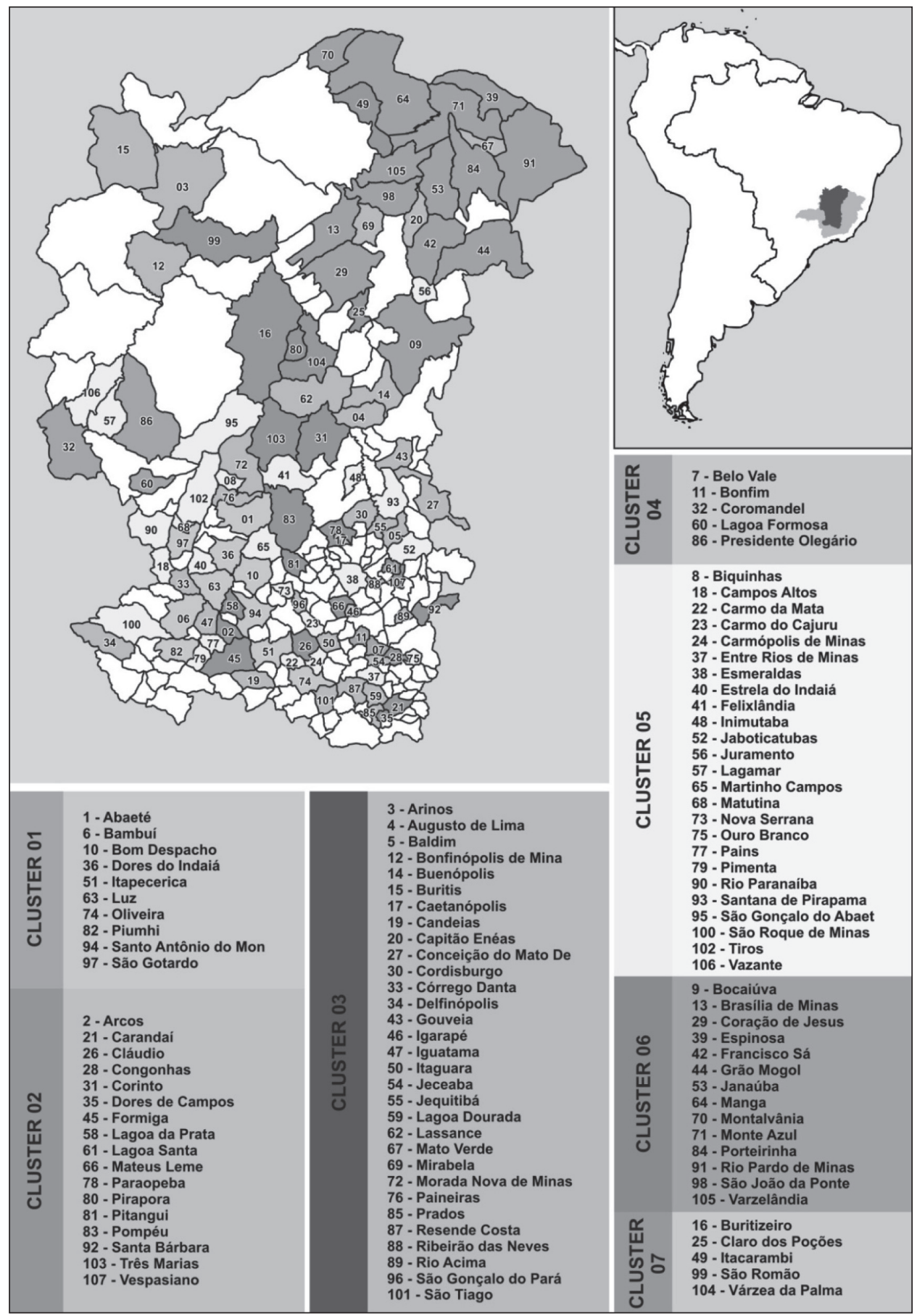

Fonte: Elaborado pelos autores. 


\subsection{Impactos socioeconômicos do Projeto Gorutuba}

\subsubsection{Crescimento populacional}

A implantação de um projeto público de irrigação bem como toda a infraestrutura necessária para a exploração da atividade agrícola irrigada e escoamento de sua produção deveriam contribuir para o crescimento populacional de Porteirinha e para a ocupação da região Norte do estado de Minas Gerais, que na década de 1970 era caracterizada por grandes vazios demográficos. Os dados da tabela 4 demonstram que $75 \%$ dos municípios do grupo controle apresentaram crescimento populacional no recorte temporal. Apenas os municípios de Francisco Sá, Grão Mogol e Montalvânia não apresentaram crescimento populacional.

Com relação ao município beneficiado, nota-se que a taxa média de crescimento apresentada por Porteirinha foi de $32,1 \%$ no período de 1970 a 2000, enquanto a média do grupo controle foi de $23,3 \%$ no mesmo período. Isto sugere um desempenho superior no município beneficiado em relação ao grupo controle.

A análise interperíodo demonstra que, na década anterior à implantação do Projeto Gorutuba (1970-80), o município de Porteirinha, o mais populoso (primeiro no ranking de 1970 e 1980), apresentou a sexta maior taxa geométrica de crescimento populacional anual. Já na década seguinte (1980-91), após a implantação do projeto de irrigação, houve um acréscimo expressivo na taxa de crescimento populacional em Porteirinha; o município apresentou a segunda maior taxa geométrica de crescimento anual da população entre os municípios do cluster 6, de 1,44\%. No entanto, na década seguinte (1991-2000) não houve grande variação nas taxas de crescimento populacional de Porteirinha. Nesse sentido, percebe-se que houve um aumento expressivo da população de Porteirinha, principalmente nas fases de implantação e ocupação do Projeto Gorutuba, isto é, entre 1978 e meados da década de 1990.

Destaca-se, também, o crescimento populacional de Janaúba, que apresentou a maior taxa média de crescimento relativo (103,1\%) entre os municípios do grupo controle. Esse crescimento foi influenciado pela implantação do Projeto Gorutuba e pela construção da barragem Bico da Pedra, que abastece o Perímetro Irrigado e a cidade de Janaúba.

O Projeto de Irrigação e a parte urbana do município de Nova Porteirinha, onde atualmente localiza-se o projeto, estão muito mais próximos do município de Janaúba do que de Porteirinha, sendo separados apenas por duas pontes sobre o rio Gorutuba. Assim, os impactos do Projeto Gorutuba refletem-se diretamente no município de Janaúba que, por sua proximidade e característica, tornou-se um polo de referência para a região em relação aos serviços e ao comércio. 


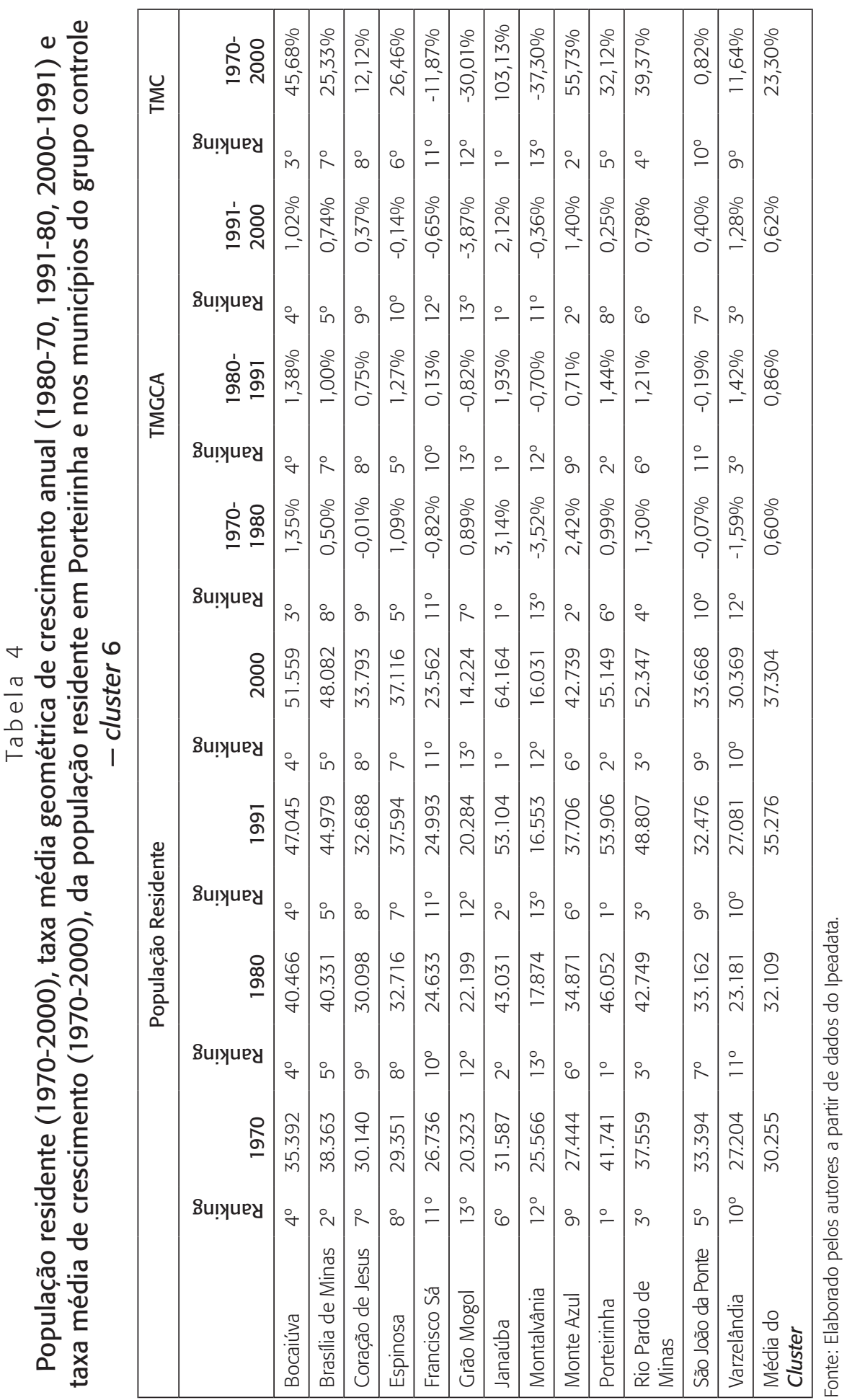




\subsubsection{Produção agropecuária}

O impacto do Projeto Gorutuba na produção agropecuária do município de Porteirinha foi analisado por meio do comportamento do PIB agropecuária (Tabela 5). Em 1970, o município de Porteirinha possuía o terceiro maior PIB da atividade agropecuária dentre os municípios do cluster, em 2000 Porteirinha subiu uma posição, apresentando o segundo maior PIB agropecuária do cluster 6.

Tabela 5

PIB Atividade Agropecuária - R\$ 2000 (mil) deflacionado pelo fator implícito do PIB Nacional em Porteirinha e nos municípios do grupo controle - cluster 6 (1970-2000)

\begin{tabular}{|c|c|c|c|c|c|c|c|c|c|c|c|c|}
\hline & 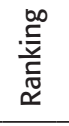 & 1970 & 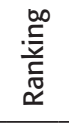 & 1975 & 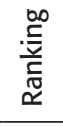 & 1980 & 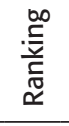 & 1985 & 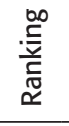 & 1996 & 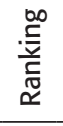 & 2000 \\
\hline 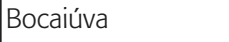 & $4^{\circ}$ & $16.235,34$ & $7^{\circ}$ & $19.430,50$ & $5^{\circ}$ & $25.541,93$ & $1^{\circ}$ & $53.429,94$ & $2^{\circ}$ & $32.298,98$ & $3^{0}$ & 84 \\
\hline Minas & $5^{\circ}$ & $12.956,49$ & $11^{\circ}$ & $10.727,45$ & $8^{\circ}$ & $15.385,31$ & $12^{\circ}$ & 822,40 & $10^{\circ}$ & $16.714,97$ & $9^{\circ}$ & 5,87 \\
\hline Coração & $7^{\circ}$ & $11.502,10$ & $12^{\circ}$ & $10.520,35$ & $12^{\circ}$ & $12.491,21$ & $8^{\circ}$ & $21.986,62$ & $5^{\circ}$ & $22.753,43$ & $6^{\circ}$ & $20.800,59$ \\
\hline spin & $8^{\circ}$ & $11.360,88$ & $13^{\circ}$ & $9.673,08$ & $9^{\circ}$ & $15.253,39$ & $9^{\circ}$ & $17.490,59$ & $12^{\circ}$ & $9.977,43$ & $12^{\circ}$ & ,91 \\
\hline Sá & $6^{\circ}$ & $14.833,98$ & $3^{\circ}$ & 25.78 & $6^{\circ}$ & 24.725 & $6^{\circ}$ & $28.477,24$ & $6^{\circ}$ & $22.607,52$ & $7^{\circ}$ & 10 \\
\hline Grão Mogol & $13^{\circ}$ & $5.297,49$ & $5^{0}-$ & $21.558,73$ & $11^{\circ}$ & $14.239,68$ & $10^{\circ}$ & $15.027,64$ & $1^{\circ}$ & $57.257,63$ & $10^{\circ}$ & $13.306,95$ \\
\hline Janaúba & $1^{\circ}$ & $26.074,21$ & $1^{\circ}$ & $28.360,40$ & $2^{\circ}$ & $49.442,03$ & $4^{\circ}$ & $35.529,46$ & $7^{\circ}$ & $20.956,98$ & $4^{\circ}$ & $24.102,42$ \\
\hline Montalvânia & $9^{\circ}$ & $10.282,73$ & $8^{\circ}$ & $15.569,51$ & $13^{\circ}$ & $10.016,42$ & $13^{\circ}$ & $7.547,50$ & $13^{\circ}$ & $3.456,52$ & $13^{\circ}$ & 97,91 \\
\hline Monte Azul & $10^{\circ}$ & $8.645,54$ & $9^{\circ}$ & 15.2 & $7^{\circ}$ & 26 & $5^{\circ}$ & $30.054,28$ & $11^{\circ}$ & $13.597,77$ & $1^{\circ}$ & $29.953,95$ \\
\hline Porteirinha & $3^{\circ}$ & $16.560,71$ & $4^{\circ}-$ & $22.418,09$ & $4^{\circ}$ & $26.322,26$ & $2^{\circ}$ & $49.078,83$ & $3^{0}$ & $31.123,11$ & $2^{\circ}$ & $26.727,37$ \\
\hline Rio Pardo de Minas & $12^{\circ}$ & $7.351,37$ & $2^{\circ}$ & $27.669,76$ & $1^{\circ}$ & $58.742,93$ & $3^{0}$ & $43.891,59$ & $4^{\circ}$ & $30.439,65$ & $5^{\circ}$ & $21.115,17$ \\
\hline São João da Ponte & $2^{\circ}$ & $24.751,49$ & $6^{\circ}$ & $20.605,04$ & $3^{0}$ & $38.354,79$ & $7^{\circ}$ & $22.633,00$ & $9^{\circ}$ & $16.382,78$ & $11^{\circ}$ & $12.004,94$ \\
\hline Varzelândia & $11^{\circ}$ & $8.644,24$ & $10^{\circ}$ & $11.326,78$ & $10^{\circ}$ & $15.086,61$ & $11^{\circ}$ & $12.424,63$ & $8^{\circ}$ & $17.198,00$ & $8^{\circ}$ & $15.574,25$ \\
\hline Média do Cluster & & $13.161,32$ & & $18.039,12$ & & $25.173,35$ & & $24.692,91$ & & $21.970,14$ & & $17.483,91$ \\
\hline
\end{tabular}

Fonte: Elaborado pelos autores a partir de dados do Ipeadata.

Entre os períodos de 1970 a 2000, a taxa de crescimento relativa do PIB agropecuária de 1970 para 2000 foi de 61,39\%, valor este superior à média apresentada pelo grupo controle (32,84\%). De acordo com os dados da tabela 6, antes da implantação do perímetro irrigado entre os períodos de 1970-75 e 1975-80, o PIB agropecuária de Porteirinha apresentou crescimento a taxas decrescentes, enquanto os demais municípios do cluster 6 apresentaram crescimento a taxas crescentes.

Em Porteirinha, após a implantação do Projeto Gorutuba, no período de 1980-85 o PIB agropecuária apresentou taxa média de crescimento anual de 13,27\%, segundo maior valor 
entre os municípios do cluster 6. Nos outros 13 municípios que compõem o cluster a taxa média de crescimento anual do PIB agropecuário foi negativa $(-0,38 \%)$. O desempenho positivo do município beneficiado pela implantação do Projeto Gorutuba em relação ao desempenho médio dos municípios do grupo de controle possivelmente está associado à expansão da fronteira agrícola, ocorrida principalmente pela implantação da agricultura irrigada.

\section{Tabela 6}

Taxa média geométrica de crescimento anual (1970-75, 1980/1975, 1985-80, 1996-85 e 2000-1996) e taxa média de crescimento (1970-2000) do PIB Atividade Agropecuária em Porteirinha e nos municípios do grupo controle - cluster 6

\begin{tabular}{|c|c|c|c|c|c|c|c|c|c|c|c|c|}
\hline & \multicolumn{10}{|c|}{ TMGCA } & \multicolumn{2}{|r|}{ TMC } \\
\hline & 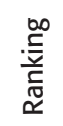 & $\begin{array}{c}1970- \\
1975\end{array}$ & 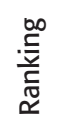 & $\begin{array}{l}1975- \\
1980\end{array}$ & 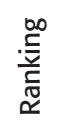 & $\begin{array}{c}1980- \\
1985\end{array}$ & 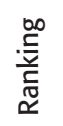 & $\begin{array}{c}1985- \\
1996\end{array}$ & 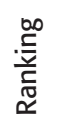 & $\begin{array}{l}1996- \\
2000\end{array}$ & 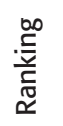 & $\begin{array}{l}1970- \\
2000\end{array}$ \\
\hline Bocaiúva & $8^{\circ}$ & $3,66 \%$ & $8^{\circ}$ & $5,62 \%$ & $1^{\circ}$ & $15,91 \%$ & $9^{\circ}$ & $-4,47 \%$ & $9^{\circ}$ & $-3,74 \%$ & $6^{\circ}$ & $64,39 \%$ \\
\hline Brasília de Minas & $13^{\circ}$ & $-3,71 \%$ & $6^{\circ}$ & $7,48 \%$ & $13^{\circ}$ & $-12,65 \%$ & $2^{\circ}$ & $7,15 \%$ & $7^{\circ}$ & $-2,40 \%$ & $8^{\circ}$ & $14,28 \%$ \\
\hline Coração de Jesus & $10^{\circ}$ & $-1,77 \%$ & $9^{\circ}$ & $3,49 \%$ & $3^{\circ}$ & $11,97 \%$ & $4^{\circ}$ & $0,31 \%$ & $4^{\circ}$ & $-1,78 \%$ & $4^{\circ}$ & $80,84 \%$ \\
\hline Espinosa & $11^{\circ}$ & $-3,17 \%$ & $4^{\circ}$ & $9,54 \%$ & $6^{\circ}$ & $2,78 \%$ & $11^{\circ}$ & $-4,98 \%$ & $6^{\circ}$ & $-2,01 \%$ & $11^{\circ}$ & $-20,68 \%$ \\
\hline Francisco Sá & $4^{\circ}$ & $11,69 \%$ & $11^{\circ}$ & $-0,84 \%$ & $5^{\circ}$ & $2,87 \%$ & $5^{\circ}$ & $-2,08 \%$ & $11^{\circ}$ & $-6,52 \%$ & $9^{\circ}$ & $8,82 \%$ \\
\hline Grão Mogol & $1^{\circ}$ & $32,41 \%$ & $12^{\circ}$ & $-7,96 \%$ & $7^{\circ}$ & $1,08 \%$ & $1^{\circ}$ & $12,93 \%$ & $13^{\circ}$ & $-25,31 \%$ & $3^{0}$ & $151,19 \%$ \\
\hline Janaúba & $9^{\circ}$ & $1,70 \%$ & $3^{\circ}$ & $11,76 \%$ & $11^{\circ}$ & $-6,40 \%$ & $10^{\circ}$ & $-4,69 \%$ & $3^{\circ}$ & $2,84 \%$ & $10^{\circ}$ & $-7,56 \%$ \\
\hline Montalvânia & $5^{\circ}$ & $8,65 \%$ & $13^{\circ}$ & $-8,44 \%$ & $9^{\circ}$ & $-5,50 \%$ & $12^{\circ}$ & $-6,85 \%$ & $2^{\circ}$ & $12,75 \%$ & $12^{\circ}$ & $-38,75 \%$ \\
\hline Monte Azul & $3^{\circ}$ & $12,00 \%$ & $5^{\circ}$ & $8,39 \%$ & $4^{\circ}$ & $5,68 \%$ & $13^{\circ}$ & $-6,96 \%$ & $1^{\circ}$ & $17,11 \%$ & $1^{\circ}$ & $246,47 \%$ \\
\hline Porteirinha & $6^{\circ}$ & $6,24 \%$ & $10^{\circ}$ & $3,26 \%$ & $2^{\circ}$ & $13,27 \%$ & $8^{\circ}$ & $-4,06 \%$ & $8^{\circ}$ & $-3,00 \%$ & $7^{\circ}$ & $61,39 \%$ \\
\hline Rio Pardo de Minas & $2^{\circ}$ & $30,35 \%$ & $1^{\circ}$ & $16,25 \%$ & $10^{\circ}$ & $-5,66 \%$ & $7^{\circ}$ & $-3,27 \%$ & $12^{\circ}$ & $-7,05 \%$ & $2^{\circ}$ & $187,23 \%$ \\
\hline São João da Ponte & $12^{\circ}$ & $-3,60 \%$ & $2^{\circ}$ & $13,23 \%$ & $12^{\circ}$ & $-10,01 \%$ & $6^{\circ}$ & $-2,90 \%$ & $10^{\circ}$ & $-6,03 \%$ & $13^{\circ}$ & $-51,50 \%$ \\
\hline Varzelândia & $7^{\circ}$ & $5,55 \%$ & $7^{\circ}$ & $5,90 \%$ & $8^{\circ}$ & $-3,81 \%$ & $3^{\circ}$ & $3,00 \%$ & $5^{\circ}$ & $-1,96 \%$ & $5^{\circ}$ & $80,17 \%$ \\
\hline Média do Cluster & & $6,51 \%$ & & $6,89 \%$ & & $-0,38 \%$ & & $-1,06 \%$ & & $-4,47 \%$ & & $32,84 \%$ \\
\hline
\end{tabular}

Fonte: Elaborado pelos autores a partir de dados do Ipeadata.

Nos períodos subsequentes, houve declínio expressivo das taxas anuais de crescimento do PIB agropecuária médio do grupo controle e de Porteirinha (tabela 6), determinado principalmente pela epidemia de Mal-do-Panamá, que atingiu a principal cultura do Projeto Gorutuba, a banana, desde o fim da década de 1980 até meados da década de 1990. Essa epidemia provocou enormes prejuízos não só aos produtores deste perímetro, como também a vários produtores de outros perímetros irrigados da bacia do rio São Francisco na região Norte do estado de Minas Gerais, fazendo com que muitos produtores abandonassem a atividade agropecuária. 


\subsubsection{Geração de empregos}

Há de se observar que, de acordo com Valdes e colaboradores (2004), o investimento por posto de trabalho, gerado pela agricultura irrigada, é relativamente baixo em comparação com os outros setores da economia. Ainda segundo esses autores obtém-se, em média, um emprego on farm para cada hectare irrigado (emprego direto) e, aproximadamente, 1,5 posto de trabalho adicional em atividades indiretas (empregos indiretos), para frente ou para trás na cadeia de produção, a um custo médio de U\$ 5 mil a U\$ 6 mil. Nesse sentido, torna-se visível a participação dos projetos públicos de irrigação como fonte de geração de empregos no município e, consequentemente, a contribuição para diminuição da pobreza na região.

Entretanto, de acordo com o Levantamento da Situação do Perímetro Irrigado do Gorutuba realizado pela Codevasf em 2005, a geração de emprego no perímetro irrigado é de apenas 0,62 por hectare. Este baixo desempenho na geração de emprego direto ocorre devido ao número de lotes ociosos, pois o coeficiente de utilização de terra no perímetro é apenas 0,62 .

Conforme pesquisa realizada por Adami e Reis (2008), 70\% dos empresários do Perímetro Irrigado do Gorutuba empregavam mão de obra permanente e 47,4\% utilizavam mão de obra temporária. Além disso, 65,6\% dos empresários possuíam mais de 10 funcionários. No que diz respeito ao salário, $88,9 \%$ dos empregados recebiam diárias nos valores de $\mathrm{R} \$$ 13,00 e $R \$ 15,00$, correspondendo a um salário médio de $R \$ 425,00$, cujo valor modal é de $R \$$ $380,00 .^{3}$ Quanto aos colonos, estes não se destacaram como geradores de emprego, pois suas glebas possuem áreas reduzidas ( 5 ha) e cujo objetivo na concepção original do projeto foi a ocupação da mão de obra familiar. Mesmo assim, 10\% dos colonos entrevistados mantinham empregados permanentes. No entanto, quando se trata de empregos temporários, os números aumentam para 49,2\%, com o pagamento de uma diária de $\mathrm{R} \$ 12,00$ a $\mathrm{R} \$ 15,00$ (Adami e Reis, 2008).

Na comparação de Porteirinha com os municípios do grupo controle observa-se, na tabela 7, que apenas três municípios do grupo controle (Brasília de Minas, Monte Azul e Rio Pardo de Minas) apresentaram crescimento no número de pessoas ocupadas no campo, no período de 1970 a 2000. Os nove municípios restantes do grupo controle mais Porteirinha apresentaram uma queda no número de pessoas trabalhando na área rural.

Estes dados podem sugerir uma baixa contribuição do Projeto Gorutuba para geração de empregos diretos na área rural de Porteirinha. Não obstante, deve-se levar em consideração que a queda percentual na geração de emprego na área rural do município de Porteirinha $(-6,08 \%)$ foi inferior à queda média apresentada pelo grupo controle $(-20,21 \%)$.

\footnotetext{
${ }^{3}$ Em 2008, o valor do salário mínimo nacional era de quatrocentos e quinze reais $(\mathrm{R} \$ 415,00)$.
} 


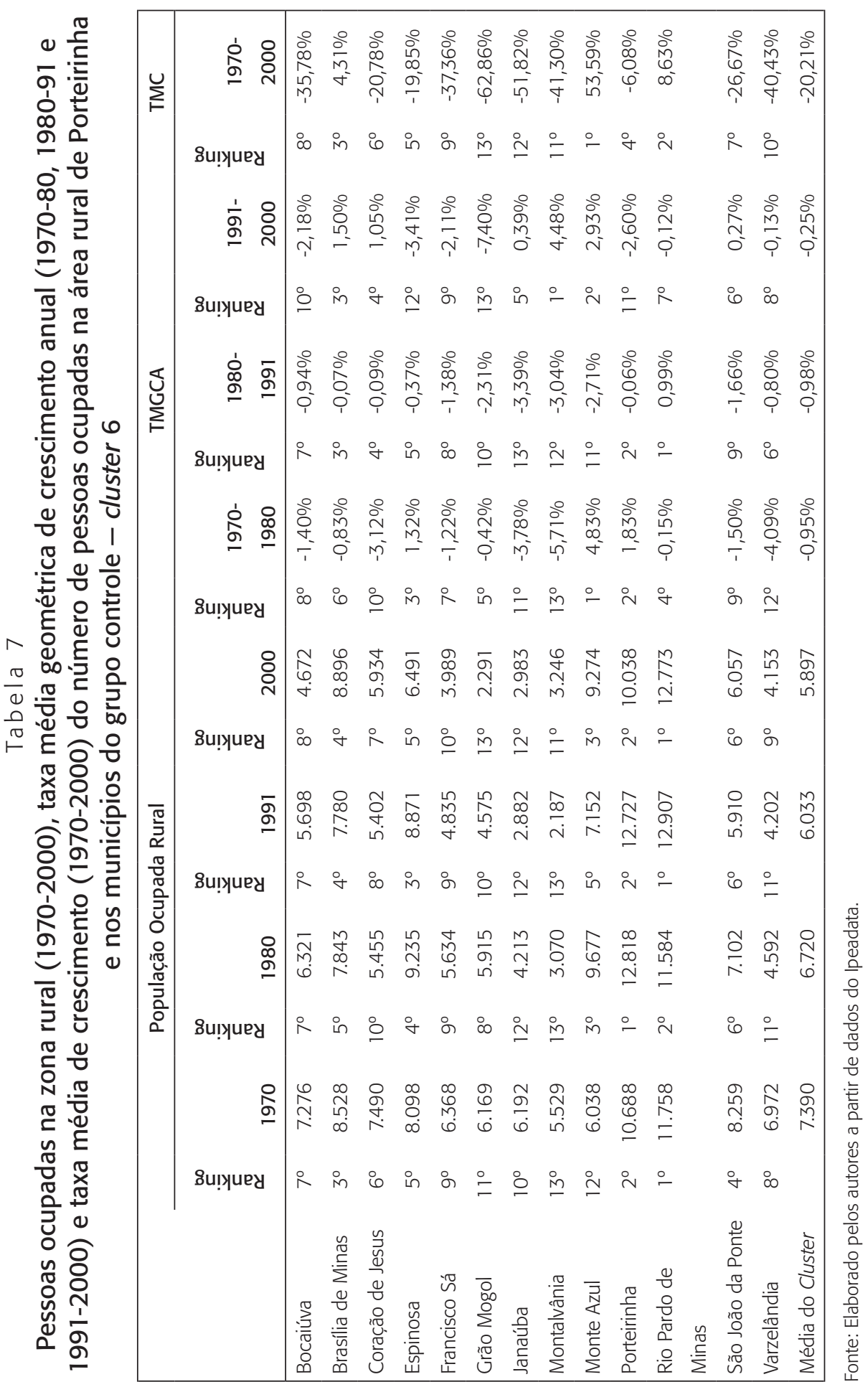


Outro aspecto a ser analisado são as taxas de crescimento interperíodos. Ressalta-se que na década anterior à implantação do perímetro irrigado (1970-80) e no período de 198091 os municípios do grupo de controle apresentaram taxas médias negativas de crescimento anual no número de pessoas ocupadas na área rural. Enquanto o município de Porteirinha apresentou a segunda maior taxa de crescimento anual no período (1970-80), que ocorre nos primeiros anos de implantação e funcionamento do Projeto Gorutuba e, em seguida, houve uma pequena redução no período de 1980 a 1991, mas é no período de 1991 a 2000 que ocorre a maior redução do número de pessoas ocupadas no campo, com um decréscimo de 2,6\% ao ano. Novamente, este resultado está relacionado aos efeitos do Mal-do-Panamá, que contribuiu para a redução no número de empregos, do coeficiente de uso da terra.

\subsubsection{Desenvolvimento}

Na busca de verificar os impactos do Projeto Gorutuba no desenvolvimento do município de Porteirinha, utilizou-se o Índice de Desenvolvimento Humano (IDH), criado no início da década de 1990 pelo Programa das Nações Unidas para o Desenvolvimento (PNUD). Este índice combina três componentes básicos do desenvolvimento humano: a longevidade, a educação e a renda. A metodologia de cálculo do IDH envolve a transformação destas três dimensões em índices, que variam entre 0 (pior) e 1 (melhor), bem como a combinação desses índices em um indicador síntese.

Deve-se ratificar que a análise do impacto de um projeto de irrigação ou de qualquer outro programa do governo sobre o Índice de Desenvolvimento Humano municipal requer certa cautela. Conforme mencionado anteriormente, o IDH é uma combinação de índices que abrangem diversas dimensões, a saber: educação, saúde, condições e expectativa de vida dos indivíduos. Dessa forma, torna-se complexo isolar o efeito de variáveis externas ao projeto sobre a evolução do IDH municipal.

Não obstante, julga-se necessário, mesmo que de maneira imprecisa, avaliar o comportamento deste indicador antes e após a implantação do projeto, por meio da comparação entre o município beneficiado (Porteirinha) e o grupo controle, ou seja, os demais municípios que compõem o cluster 6.

O subíndice do IDH relativo a educação considera a taxa de alfabetização de pessoas e a taxa bruta de frequência à escola, bem como examina a parcela da população local que vai à escola em comparação com a população local em idade escolar. A partir dos dados apresentados na tabela 8 nota-se um comportamento semelhante nas variações dos IDH - educação em todos os municípios pesquisados. Ressalta-se a considerável evolução na taxa relativa de crescimento do IDH educação no período de 1970-2000, mas sempre com comportamento semelhante, o que leva a admitir uma baixa influência do projeto na área da educação.

Em 1970, o município de Porteirinha apresentava um baixo nível de desenvolvimento humano na área de educação com um índice de 0,286 (quarto maior índice do cluster), e 
todos os municípios do cluster apresentaram IDH inferior a 0,499, com IDH educação médio de 0,240 nesse mesmo ano. Enquanto isso, no ano de 2000, o IDH médio do cluster $(0,715)$ evoluiu de baixo para médio (entre 0,501 e 0,799). Novamente, todos os municípios do grupo apresentaram uma evolução semelhante com o mesmo nível de desenvolvimento. O município com maior IDH educação foi Bocaiúva $(0,777)$, enquanto o que apresentou o indicador mais baixo foi Rio Pardo de Minas $(0,674)$, o que representa uma diferença de 0,103.

Tabela 8

IDH Educação (1970-2000), taxa média geométrica de crescimento anual (1970-80, 1980-91 e 1991-2000) e taxa média de crescimento (1970-2000) do IDH Educação em Porteirinha e nos municípios do grupo controle - cluster 6

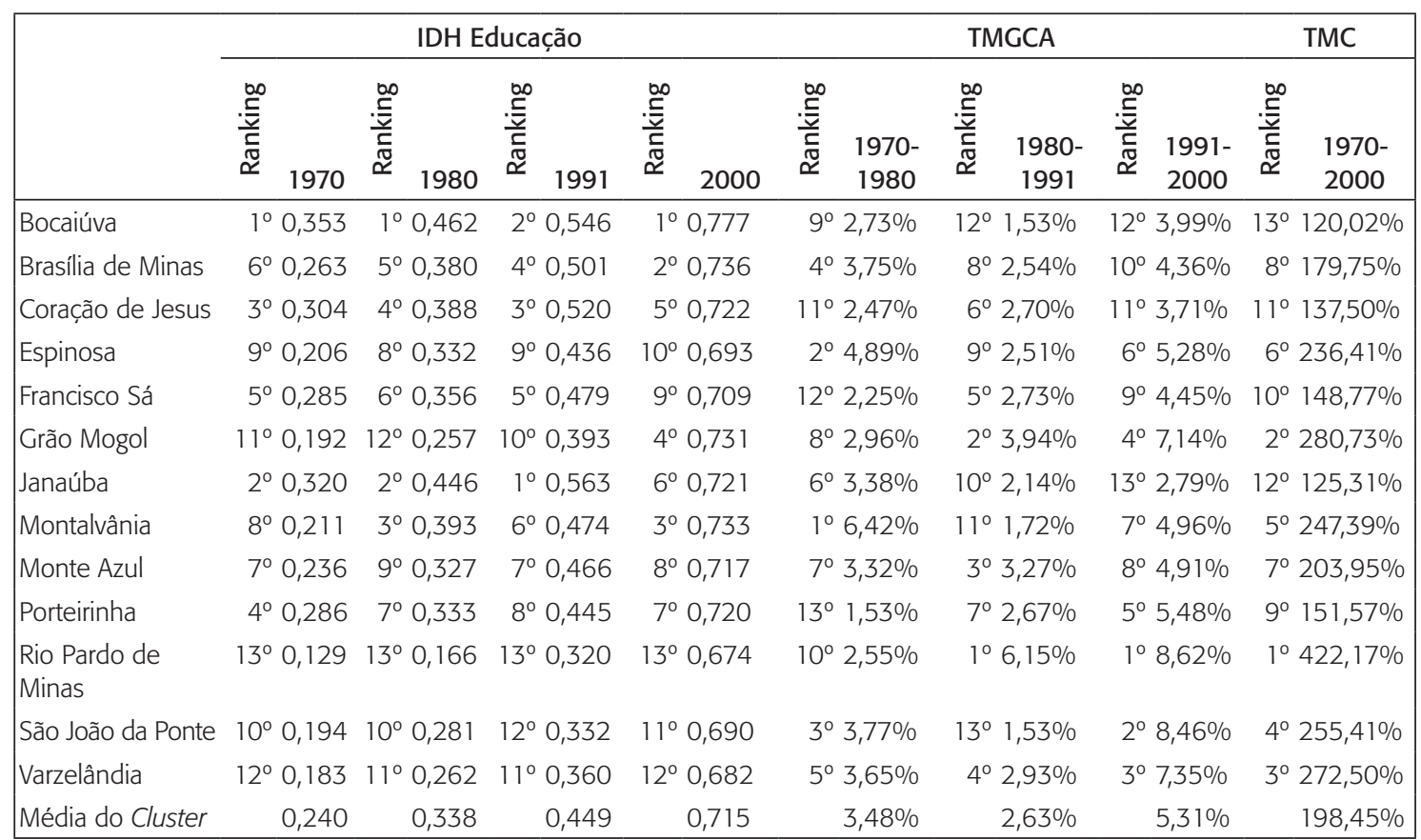

Fonte: Elaborado pelos autores, a partir de dados do Ipeadata.

Entre os períodos de 1970-80, o município de Porteirinha apresentou uma taxa de crescimento anual de 1,53\%, enquanto os demais municípios do cluster 6 tiveram uma taxa geométrica de crescimento anual de 3,48\%. Nos períodos seguintes de 1980-91 e 1991-2000, posteriores à implantação do perímetro irrigado, Porteirinha apresentou taxas médias de crescimento anuais do IDH educação superiores às taxas médias do grupo controle.

Para avaliar os impactos na saúde, analisou-se o subíndice IDH longevidade, que é obtido a partir do indicador esperança de vida ao nascer, através da fórmula: (valor observado do indicador — limite inferior) / (limite superior - limite inferior), em que os limites inferiores e superiores são equivalentes a 25 e 85 anos, respectivamente (PNUD, 2004). Os dados do 
IDH longevidade, apresentados na tabela 9, demonstram uma situação similar à observada na análise do IDH educação.

Tabela 9

IDH Longevidade (1970-2000), taxa média geométrica de crescimento anual (1970-80, 1980-91 e 1991-2000) e taxa média de crescimento (1970-2000) do IDH Longevidade em Porteirinha e nos municípios do grupo controle - cluster 6

\begin{tabular}{|c|c|c|c|c|c|c|c|c|c|c|c|c|c|c|c|c|}
\hline & \multicolumn{8}{|c|}{ IDH Longevidade } & \multicolumn{6}{|c|}{ TMGCA } & \multicolumn{2}{|r|}{ TMC } \\
\hline & 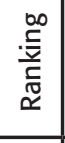 & 1970 & 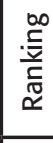 & 1980 & 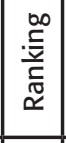 & 1991 & 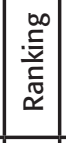 & 2000 & 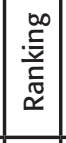 & \begin{tabular}{|c|}
$1970-$ \\
1980 \\
\end{tabular} & 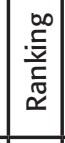 & \begin{tabular}{|c}
$1980-$ \\
1991 \\
\end{tabular} & 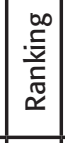 & \begin{tabular}{|l}
$1991-$ \\
2000 \\
\end{tabular} & 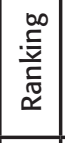 & $\begin{array}{l}1970- \\
2000 \\
\end{array}$ \\
\hline Bocaiúva & $2^{\circ}$ & 0,494 & $5^{\circ}$ & 0,541 & $7^{\circ}$ & 0,625 & $1^{\circ}$ & 0,770 & $12^{\circ}$ & $0,91 \%$ & $7^{\circ}$ & $1,32 \%$ & $1^{\circ}$ & $2,34 \%$ & $9^{\circ}$ & $55,80 \%$ \\
\hline Brasília de Minas & $1^{\circ}$ & 0,522 & $1^{\circ}$ & 0,585 & $5^{\circ}$ & 0,644 & $6^{\circ}$ & 0,707 & $10^{\circ}$ & $1,15 \%$ & $12^{\circ}$ & $0,88 \%$ & $11^{\circ}$ & $1,05 \%$ & $13^{\circ}$ & $35,49 \%$ \\
\hline Coração de Jesus & $4^{\circ}$ & 0,470 & $2^{\circ}$ & 0,553 & $3^{\circ}$ & 0,646 & $4^{\circ}$ & 0,721 & $8^{\circ}$ & $1,64 \%$ & $6^{\circ}$ & $1,42 \%$ & $8^{\circ}$ & $1,23 \%$ & $10^{\circ}$ & $53,40 \%$ \\
\hline Espinosa & $3^{0}$ & 0,485 & $4^{\circ}$ & 0,548 & $10^{\circ}$ & 0,591 & $9^{\circ}$ & 0,682 & $9^{\circ}$ & $1,23 \%$ & $13^{\circ}$ & $0,69 \%$ & $5^{\circ}$ & $1,60 \%$ & $11^{\circ}$ & $40,62 \%$ \\
\hline Francisco Sá & $5^{\circ}$ & 0,461 & $8^{\circ}$ & 0,503 & $6^{\circ}$ & 0,626 & $3^{\circ}$ & 0,733 & $13^{\circ}$ & $0,88 \%$ & $4^{\circ}$ & $2,01 \%$ & $4^{\circ}$ & $1,77 \%$ & $8^{\circ}$ & $59,00 \%$ \\
\hline Grão Mogol & $9^{\circ}$ & 0,409 & $6^{\circ}$ & 0,526 & $1^{\circ}$ & 0,676 & $2^{\circ}$ & 0,747 & $6^{\circ}$ & $2,55 \%$ & $2^{\circ}$ & $2,31 \%$ & $10^{\circ}$ & $1,12 \%$ & $2^{\circ}$ & $82,64 \%$ \\
\hline Janaúba & $13^{\circ}$ & 0,358 & $13^{\circ}$ & 0,479 & $4^{\circ}$ & 0,646 & $5^{\circ}$ & 0,720 & $2^{\circ}$ & $2,95 \%$ & $1^{\circ}$ & $2,76 \%$ & $9^{\circ}$ & $1,21 \%$ & $1^{\circ}$ & $101,12 \%$ \\
\hline \begin{tabular}{|l|} 
Montalvânia \\
\end{tabular} & $10^{\circ}$ & 0,389 & $9^{\circ}$ & 0,505 & $12^{\circ}$ & 0,567 & $10^{\circ}$ & 0,673 & $5^{\circ}$ & $2,64 \%$ & $11^{\circ}$ & $1,06 \%$ & $2^{\circ}$ & $1,92 \%$ & $5^{\circ}$ & $73,01 \%$ \\
\hline Monte Azul & $12^{\circ}$ & 0,365 & $12^{\circ}$ & 0,491 & $13^{\circ}$ & 0,557 & $12^{\circ}$ & 0,655 & $1^{\circ}$ & $3,01 \%$ & $9^{\circ}$ & $1,15 \%$ & $3^{\circ}$ & $1,81 \%$ & $3^{\circ}$ & $79,36 \%$ \\
\hline Porteirinha & $11^{\circ}$ & 0,375 & $10^{\circ}$ & 0,500 & $11^{\circ}$ & 0,575 & $11^{\circ}$ & 0,662 & $3^{\circ}$ & $2,92 \%$ & $8^{\circ}$ & $1,28 \%$ & $6^{\circ}$ & $1,58 \%$ & $4^{\circ}$ & $76,60 \%$ \\
\hline Rio Pardo de Minas & $6^{0}$ & 0,452 & $11^{\circ}$ & 0,498 & $9^{\circ}$ & 0,612 & $13^{\circ}$ & 0,625 & $11^{\circ}$ & $0,97 \%$ & $5^{\circ}$ & $1,89 \%$ & $13^{\circ}$ & $0,23 \%$ & $12^{\circ}$ & $38,27 \%$ \\
\hline São João da Ponte & $7^{\circ}$ & 0,421 & $3^{\circ}$ & 0,553 & $8^{\circ}$ & 0,622 & $7^{\circ}$ & 0,701 & $4^{\circ}$ & $2,76 \%$ & $10^{\circ}$ & $1,07 \%$ & $7^{\circ}$ & $1,34 \%$ & $7^{\circ}$ & $66,51 \%$ \\
\hline Varzelândia & $8^{\circ}$ & 0,414 & $7^{\circ}$ & 0,518 & $2^{\circ}$ & 0,649 & $8^{\circ}$ & 0,697 & $7^{\circ}$ & $2,27 \%$ & $3^{\circ}$ & $2,07 \%$ & $12^{\circ}$ & $0,80 \%$ & $6^{\circ}$ & $68,36 \%$ \\
\hline Média do Cluster & & 0,437 & & 0,525 & & 0,622 & & 0,703 & & $1,86 \%$ & & $1,55 \%$ & & $1,37 \%$ & & 60,89\% \\
\hline
\end{tabular}

Fonte: Elaborado pelos autores a partir de dados do Ipeadata.

O município de Porteirinha apresentou a quarta maior taxa média de crescimento relativa no período de 1970-2000 (76,60\%) no IDH longevidade entre os municípios do cluster, sendo $60,89 \%$ a taxa média de crescimento do grupo controle. Não obstante, a posição do município em relação ao grupo controle é desfavorável antes e após a implantação do perímetro irrigado, apresentando o terceiro pior índice tanto em 1970 quanto em 2000, o que denota uma baixa influência do projeto sobre este subíndice.

Nesta pesquisa, para compreensão das condições de saúde dos produtores instalados no Projeto de Irrigação Gorutuba, foram utilizados dados primários, obtidos por meio de pesquisas de campo no perímetro irrigado realizadas por Adami e Reis (2008). De acordo com esses autores, $86,7 \%$ dos colonos recebiam visita domiciliar de algum agente de saúde, geralmente com periodicidade mensal, $66 \%$ dos colonos revelaram que suas comunidades possuem unidade de saúde, sendo o posto de saúde mais comum. Além disso, 66\% dos entrevistados declararam ter acesso a medicamento nos postos de saúde. Cerca de $70 \%$ dos respondentes classificaram o acesso à saúde como bom ou ótimo, sendo predominante a primeira classificação. 
Ademais, Adami e Reis (2008) ressaltaram as boas condições de moradia dos colonos do perímetro, fato que influencia diretamente a saúde local, reduzindo índices de mortalidade infantil e aumentando a esperança de vida na região. Em sua totalidade, as residências dos colonos eram de alvenaria com cobertura de telha ou laje, apenas 5\% possuindo piso de chão batido, o que reduz o número de determinadas doenças como a doença de Chagas e problemas respiratórios. A maioria das residências $(96,7 \%)$ possuía instalações sanitárias, 92\% das residências tinham acesso a água encanada, sendo 86,4\% oriunda da rede pública. Ainda como fator positivo, destaca-se que $85 \%$ das propriedades possuíam água tratada e apenas 3,3\% do lixo produzido nas propriedades eram deixados a céu aberto. Isto significa uma redução significativa na exposição dos indivíduos, instalados no perímetro, a doenças como verminoses, desidratação e outras (Adami e Reis, 2008).

Quanto ao impacto do Projeto Gorutuba sobre a renda, analisou-se o subíndice do IDH renda, que é obtido a partir do indicador renda per capita média. Entre os três subíndices que compõem o IDH municipal, o subíndice relativo a renda foi o que apresentou o pior desempenho entre os municípios do cluster 6 (tabela 10).

Tabela 10

IDH renda (1970-2000), taxa média geométrica de crescimento anual (1970-80, 1980-91 e 1991-2000) e taxa média de crescimento (1970-2000) do IDH Renda em Porteirinha e nos municípios do grupo controle - cluster 6

\begin{tabular}{|c|c|c|c|c|c|c|c|c|c|c|c|c|c|c|c|c|}
\hline & \multicolumn{9}{|c|}{ IDH Renda } & \multicolumn{5}{|c|}{ TMGCA } & \multicolumn{2}{|r|}{ TMC } \\
\hline & 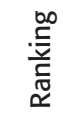 & 1970 & 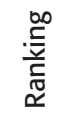 & 1980 & 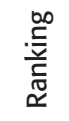 & 1991 & 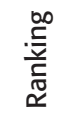 & 2000 & 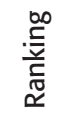 & $\begin{array}{c}1970- \\
1980\end{array}$ & 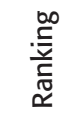 & $\begin{array}{c}1980- \\
1991\end{array}$ & 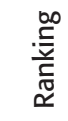 & $\begin{array}{l}1991- \\
2000\end{array}$ & 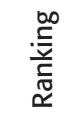 & $\begin{array}{l}1970- \\
2000\end{array}$ \\
\hline Bocaiúva & $2^{\circ}$ & 0,170 & $2^{\circ}$ & 0,510 & $3^{\circ}$ & 0,426 & $1^{\circ}$ & 0,548 & $9^{\circ}$ & $11,61 \%$ & $4^{\circ}$ & $-1,62 \%$ & $11^{\circ}$ & $2,84 \%$ & $11^{\circ}$ & $222,55 \%$ \\
\hline Brasília de Minas & $7^{\circ}$ & 0,131 & $11^{\circ}$ & 0,337 & $8^{\circ}$ & 0,250 & $11^{\circ}$ & 0,502 & $12^{\circ}$ & $9,91 \%$ & $5^{\circ}$ & $-2,68 \%$ & $7^{\circ}$ & $8,05 \%$ & $8^{\circ}$ & $283,21 \%$ \\
\hline Coração de Jesus & $10^{\circ}$ & 0,098 & $9^{\circ}$ & 0,364 & $10^{\circ}$ & 0,239 & $6^{\circ}$ & 0,532 & $4^{\circ}$ & $14,02 \%$ & $8^{\circ}$ & $-3,75 \%$ & $3^{\circ}$ & $9,30 \%$ & $4^{\circ}$ & $442,86 \%$ \\
\hline Espinosa & $8^{\circ}$ & 0,125 & $3^{\circ}$ & 0,451 & $6^{\circ}$ & 0,274 & $3^{\circ}$ & 0,542 & $5^{\circ}$ & $13,69 \%$ & $11^{\circ}$ & $-4,43 \%$ & $8^{\circ}$ & $7,86 \%$ & $6^{\circ}$ & $333,20 \%$ \\
\hline Francisco Sá & $1^{\circ}$ & 0,176 & $4^{\circ}$ & 0,428 & $5^{\circ}$ & 0,308 & $2^{\circ}$ & 0,545 & $13^{\circ}$ & $9,29 \%$ & $7^{\circ}$ & $-2,95 \%$ & $9^{\circ}$ & $6,55 \%$ & $13^{\circ}$ & $209,66 \%$ \\
\hline Grão Mogol & $11^{\circ}$ & 0,079 & $8^{\circ}$ & 0,368 & $4^{\circ}$ & 0,324 & $4^{\circ}$ & 0,539 & $2^{\circ}$ & $16,63 \%$ & $3^{\circ}$ & $-1,15 \%$ & $10^{\circ}$ & $5,82 \%$ & $3^{\circ}$ & $582,28 \%$ \\
\hline Janaúba & $3^{\circ}$ & 0,169 & $1^{\circ}$ & 0,600 & $2^{\circ}$ & 0,437 & $5^{\circ}$ & 0,536 & $6^{\circ}$ & $13,51 \%$ & $6^{\circ}$ & $-2,84 \%$ & $12^{\circ}$ & $2,29 \%$ & $12^{\circ}$ & $217,16 \%$ \\
\hline Montalvânia & $6^{\circ}$ & 0,135 & $5^{\circ}$ & 0,424 & $1^{\circ}$ & 0,499 & $7^{\circ}$ & 0,528 & $8^{\circ}$ & $12,13 \%$ & $1^{\circ}$ & $1,49 \%$ & $13^{\circ}$ & $0,63 \%$ & $7^{\circ}$ & $291,11 \%$ \\
\hline Monte Azul & $5^{\circ}$ & 0,137 & $7^{\circ}$ & 0,392 & $7^{\circ}$ & 0,250 & $9^{\circ}$ & 0,518 & $10^{\circ}$ & $11,09 \%$ & $9^{\circ}$ & $-4,01 \%$ & $6^{\circ}$ & $8,43 \%$ & $9^{\circ}$ & $278,10 \%$ \\
\hline Porteirinha & $4^{\circ}$ & 0,158 & $6^{\circ}$ & 0,422 & $9^{\circ}$ & 0,246 & $8^{\circ}$ & 0,528 & $11^{\circ}$ & $10,32 \%$ & $12^{\circ}$ & $-4,79 \%$ & $5^{\circ}$ & $8,86 \%$ & $10^{\circ}$ & $234,34 \%$ \\
\hline Rio Pardo de Minas & $13^{\circ}$ & 0,05 & $13^{\circ}$ & 0,205 & $11^{\circ}$ & 0,227 & $12^{\circ}$ & 0,496 & $3^{\circ}$ & $14,70 \%$ & $2^{\circ}$ & $0,93 \%$ & $4^{\circ}$ & $9,08 \%$ & $1^{\circ}$ & $854,23 \%$ \\
\hline São João da Ponte & $9^{\circ}$ & 0,101 & $10^{\circ}$ & 0,346 & $13^{\circ}$ & 0,178 & $10^{\circ}$ & 0,513 & $7^{\circ}$ & $13,10 \%$ & $13^{\circ}$ & $-5,86 \%$ & $1^{\circ}$ & $12,47 \%$ & $5^{\circ}$ & $407,43 \%$ \\
\hline Varzelândia & $12^{\circ}$ & 0,064 & $12^{\circ}$ & 0,309 & $12^{\circ}$ & 0,192 & $13^{\circ}$ & 0,469 & $1^{\circ}$ & $17,05 \%$ & $10^{\circ}$ & $-4,23 \%$ & $2^{\circ}$ & $10,44 \%$ & $2^{\circ}$ & $633,33 \%$ \\
\hline Média do Cluster & & 0,120 & & 0,395 & & 0,300 & & 0,522 & & $12,66 \%$ & & $-2,45 \%$ & & $6,34 \%$ & & $336,18 \%$ \\
\hline
\end{tabular}

Fonte: Elaborado pelos autores a partir de dados do Ipeadata. 
No ano de 1970, o IDH renda média do cluster era de 0,12 e o de Porteirinha era de 0,158 (quarto colocado), todos os municípios apresentando baixo IDH renda, isto é, inferior a 0,5. Entretanto, em 2000, o desempenho deste indicador continua precário, sendo o IDH renda média do cluster igual 0,522, enquanto o de Porteirinha foi igual a 0,528 (oitavo colocado). Embora todos os municípios do cluster 6 tenham apresentado altas taxas relativas de crescimento do IDH renda, percebe-se que o subíndice IDH renda contribui em grande parte para o baixo desempenho do desenvolvimento municipal de Porteirinha e dos demais municípios que compõem o grupo controle, pois o IDH renda apresentou os valores mais baixos entre os subíndices analisados.

A partir dos resultados apresentados e retomando os objetivos da Política Nacional de Irrigação, que pretendia contribuir para o crescimento econômico-social das regiões beneficiadas, percebe-se que a implantação do Projeto Gorutuba impactou, diretamente, o crescimento econômico da região, através do aumento na produção agrícola e consequente geração de empregos. Destaca-se o crescimento expressivo da população de Porteirinha, principalmente nas fases de implantação e ocupação do Projeto Gorutuba, isto é, entre 1978 e meados da década de 1980. Ressalta-se, também, o desempenho positivo do PIB agropecuária do município beneficiado em relação ao resultado médio dos municípios do grupo controle. Com relação à geração de empregos, a performance de Porteirinha também foi superior ao desempenho apresentado pelos municípios do grupo controle.

Em termos de impactos indiretos do perímetro irrigado sobre o desenvolvimento municipal, pouco se pode inferir. É notável a evolução dos subíndices do nível de desenvolvimento humano municipal, as taxas médias de crescimento relativo dos municípios do cluster 6, no período de 1970-2000. No entanto, como esse crescimento foi homogêneo em todos os municípios, tanto no beneficiado quanto nos municípios do grupo controle, seria inconsistente qualquer afirmação sobre o real impacto do projeto sobre o nível de desenvolvimento do município beneficiado.

Finalmente, considerando que este estudo buscou avaliar a efetividade da Política Nacional de Irrigação, especificamente do Projeto de Irrigação Gorutuba, concluiu-se que a implantação do perímetro irrigado alcança em parte os resultados esperados. Se, por um lado, são visíveis os impactos na produção agropecuária, na geração de empregos e crescimento populacional, por outro, percebe-se que o desenvolvimento econômico vigente apontou para incompatibilidade entre o crescimento econômico e a melhoria dos indicadores sociais no município beneficiado. Dessa forma, os resultados sugerem que o projeto não teve força suficiente para impulsionar os indicadores sociais, de modo que o desempenho de Porteirinha fosse mais expressivo que o dos municípios do grupo controle.

\section{Conclusões}

A abordagem multivariada demonstrou-se uma ferramenta eficiente para a redução do número de variáveis analisadas e para a definição do grupo controle. A análise demonstrou que, em 1970, o nível de desenvolvimento dos 107 municípios estudados na bacia do rio São Francisco 
em Minas Gerais era representado por quatro fatores: Rural, Urbano, Saúde e Produção Agrícola Permanente. Com relação à definição do grupo de controle, a partir da análise de cluster, o município de Porteirinha, beneficiado com a implantação do Projeto Público de Irrigação Gorutuba, ficou inserido no cluster 6. Isto significa que Porteirinha apresentava características semelhantes a outros 13 municípios (grupo controle), sendo todos pertencentes à região Norte do estado, o que pode ser considerado uma evidência do bom desempenho do modelo para formação do grupo controle.

Embora se tenha buscado analisar criteriosamente os efeitos do projeto, não foi possível avaliar sistematicamente alguns fatores tais como os impactos de outras políticas e programas públicos, indicando, mais uma vez, a dificuldade de interpretar a melhoria dos indicadores como resultantes exclusivamente da Política Nacional de Irrigação. Não obstante, nota-se que, mediante os resultados alcançados, é possível reforçar a importância da agricultura irrigada na promoção do crescimento regional; entretanto, os resultados não foram tão favoráveis para solução de sérios problemas de desigualdade social, que se fazem presentes em diversos municípios, regiões e estados brasileiros.

Como contribuição, a pesquisa forneceu subsídios, evidenciando a importância do perímetro irrigado para o crescimento econômico da região, assim como a necessidade de avaliação das políticas públicas, o que constitui importante fator para a decisão de adoção, formulação, reformulação ou suspensão de política, programas ou projetos públicos. Nesse sentido, sugere-se a realização de novos estudos utilizando novos indicadores e metodologias, para analisar os impactos socioeconômicos da Política Nacional de Irrigação. A análise de eficiência ex post, da perspectiva da análise custo-benefício ou da análise custo-efetividade, poderia ser desenvolvida para complementar a avaliação de impacto desenvolvida nesta pesquisa, uma vez que, segundo Rossi, Lipsey e Freeman (2004), pode ser considerada, mais do que uma análise alternativa, uma extensão da avaliação de impacto. Além disso, torna-se necessário que novos estudos abordem a questão dos impactos ambientais associados à implantação de projetos públicos de irrigação.

\section{Referências}

ADAMI, Thiago, H.M.; REIS, Paulo, R.C. Avaliação de políticas públicas de recursos hídricos: o caso do Projeto de Irrigação Gorutuba - MG. In: ENANPAD, 32., 2008, Rio de Janeiro. Anais... Rio de Janeiro: Anpad, 2008. p. 1-16.

BARDACH, Eugene. A practical guide for policy analysis: the eightfold path to more effective problem solving. 2. ed. Nova York: Chatham House Publishers, 2005.

BERNARDO, Salassier; SOARES, Antônio A.; MANTOVANI, Everardo C. Manual de irrigação. 7. ed. Viçosa: UFV, 2005.

CARNEIRO, Patrício A.S.; FONTES, Maurício P.F. Aspectos geográficos e agrícolas do estado de Minas Gerais. In: FONTES, Maria R.O.; FONTES, Maurício P.F. Crescimento e desigualdade regional em Minas Gerais. Viçosa, 2005. p. 249-292. 
CODEVASF. Companhia de Desenvolvimento dos Vales do São Francisco e do Parnaíba. Elenco de projetos. Disponível em <www.codevasf.gov.br/principal/perimetros-irrigados/elenco-de-projetos>. Acesso em: 15 ago. 2009.

CODEVASF. Companhia de Desenvolvimento dos Vales do São Francisco e do Parnaíba. Levantamento da situação dos perímetros irrigados, em Minas Gerais. Contrato de Consultoria no 483/04. 2005.

COHEN, Ernesto; FRANCO, Rolando. Avaliação de projetos sociais. 7. ed. Petrópolis: Vozes, 2007.

DALE, Reidar. Evaluating development programmes and projects. 2. ed. Londres: Sage Publications Inc., 2004.

DOHERTY, Tony L.; HORNE, Terry. Managing public services: implementing changes — a thoughtful approach to the practice of management. Londres: Routledge. 2002.

EMATER. Empresa de Assistência Técnica e Extensão Rural do Estado de Minas Gerais. Relatório de atividades desenvolvidas no perímetro do Gorutuba. Nova Porteirinha, 2006.

FERRO, Andrea R.; KASSOUF, Ana L. Avaliação de impacto dos programas de bolsa escola no trabalho infantil no Brasil. 2004. Disponível em: <www.cepea.esalq.usp.br/pdf/Artigo_BolsaEscola-Cepea. pdf>. Acesso em: 10 nov. 2008.

HAIR JUNIOR, Joseph F. et al. Análise multivariada de dados. Porto Alegre: Bookman, 2005.

HOLANDA, Antônio N.C. Avaliação de políticas públicas: conceitos básicos, o caso do ProInfo e a experiência brasileira. In: CONGRESSO INTERNACIONAL DEL CLAD SOBRE LA REFORMA DEL ESTADO Y DE LA ADMINISTRACIÓN PÚBLICA, 8., 2003, Panamá. Anais... Panamá: Clad, 2003. p. 28-31.

IBGE. Instituto Brasileiro de Geografia e Estatística. Área territorial oficial. Disponível em: <www. ibge.com.br/home/geociencias/areaterritorial/principal.shtm>. Acesso em: 10 out. 2009.

IPEADATA. Banco de dados do Instituto de Pesquisa Econômica Aplicada. Disponível em: <www. ipeadata.gov.br>. Acesso em: 5 nov. 2009.

MARINHO, Alexandre; FAÇANHA, Luís O. Programas sociais, eficiência e eficácia como dimensões operacionais da avaliação. Rio de Janeiro: Ipea, abr. 2001. (Texto para discussão no 787). Disponível em: <www.ipea.gov.br/pub/td/td_2001/td0787.pdf>. Acesso em: 20 nov. 2010.

MAROCO, João. Análise estatística: com utilização do SPSS. 3. ed. Lisboa: Edições Silabo, 2007.

MINGOTI, Sueli A. Análise de dados através de métodos de estatística multivariada: uma abordagem aplicada. Belo Horizonte: UFMG, 2005.

NEUBERT, Susanne. Social impact analysis of poverty alleviation programmes and projects: a contribution to the debate on the methodology of evaluation in development cooperation. Londres, Portland: Frank Cass Publishers, 2000. (GDI book series, no 14)

PASSADOR, Cláudia S.; PASSADOR, João L.; MOREIRA, Marcos. Transferência de gestão dos perímetros públicos de irrigação: uma proposta metodológica. Organizações Rurais e Agroindustriais (UFLA), v. 3, p. 40-65, set. 2009. 
PESTANA, Maria H.; GAGEIRO, João N. Análise de dados para ciências sociais: a complementaridade do SPSS. 4. ed. Lisboa: Edições Sílabo, 2005.

PMID. Plano Mineiro de Irrigação e Drenagem. Governo de Minas Gerais — governador Hélio Garcia. Jan. 1986.

PNUD. Programa das Nações Unidas para o Desenvolvimento. Desenvolvimento humano e IDH. 2004. Disponível em: <www.pnud.org.br/idh/> . Acesso em: 11 maio 2010.

PRONI. Programa Nacional de Irrigação. Governo José Sarney, 1986.

RODRIGUES, Luciene. Potencial da agricultura irrigada como indutora do desenvolvimento regional: o caso do projeto Jaíba no Norte de Minas Gerais. Revista Econômica do Nordeste, Fortaleza, v. 32, n. 2, p. 206-232, abr. 2001.

ROSSI, Peter H.; LIPSEY, Mark W.; FREEMAN, Howard E. Evaluation: a systematic approch. 7. ed. Thousand Oaks: Sage Publications, 2004.

SILVA, Elydia M.G.; FONTES, Maria R.O.; ALVES, Luiz F. Crescimento e desigualdade em Minas Gerais. In: FONTES, Maria R.O.; FONTES, Maurício P.F. Crescimento e desigualdade regional em Minas Gerais. Viçosa: UFV, 2005. p. 1-60.

SOARES, Sergei; PIANTO, Donald M. Metodologia e resultados da avaliação do programa de erradicação do trabalho infantil. Rio de Janeiro: Ipea, 2003. (Texto para Discussão n. 994). Disponível em: <www.ipea.gov.br/portal/images/stories/PDFs/TDs/td_0994.pdf>. Acesso em: 13 out. 2010.

TRIOLA, Mario F. Introdução à estatística. Rio de Janeiro: LTC, 2005.

VALDES, Alberto et al. Água Brasil: impactos e externalidades sociais da irrigação no Semi-Árido Brasileiro. Brasília: World Bank, 2004. (Série Cinco)

WHITE, Howard. Impact evaluation: the experience of the Independet Evaluation Group of the World Bank. 2007. Disponível em: <http://mpra.ub.uni-muenchen.de/1111/1/MPRA_paper_1111.pdf>. Acesso em: 15 dez. 2009.

WORLD BANK. Conducting quality impact evaluations under budget, time and data constraints. Washington 2006.

Paulo Ricardo da Costa Reis é mestrando em administração pelo Programa de Pós-Graduação em Administração da Universidade Federal de Viçosa (PPGADM/UFV). E-mails: paulo.reis@ufv.br; paulo.ufv@ hotmail.com.

Suely de Fátima Ramos Silveira é professora associada do Departamento de Administração e Contabilidade (DAD/UFV) e coordenadora do PPGADM/UFV. E-mails: sramos@ufv.br; sramos1609@gmail.com.

Pedro Eni Lourenço Rodrigues é graduado em administração pela UFV. E-mails: eni.rodrigues@ufv.br; enilourenco@hotmail.com. 